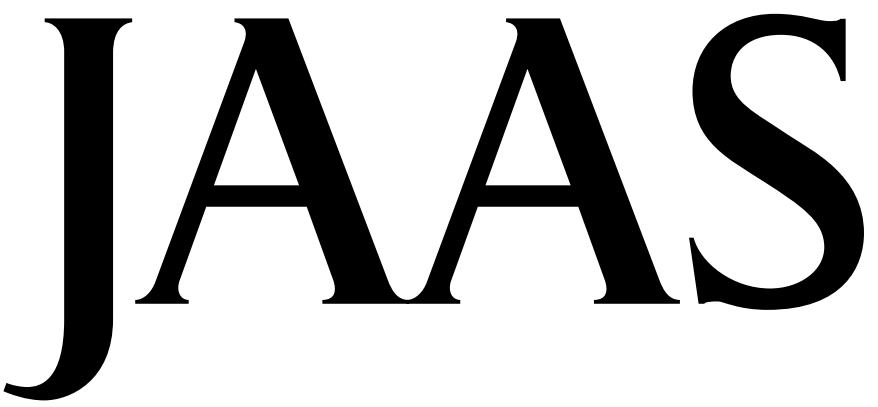

Journal of Analytical Atomic Spectrometry

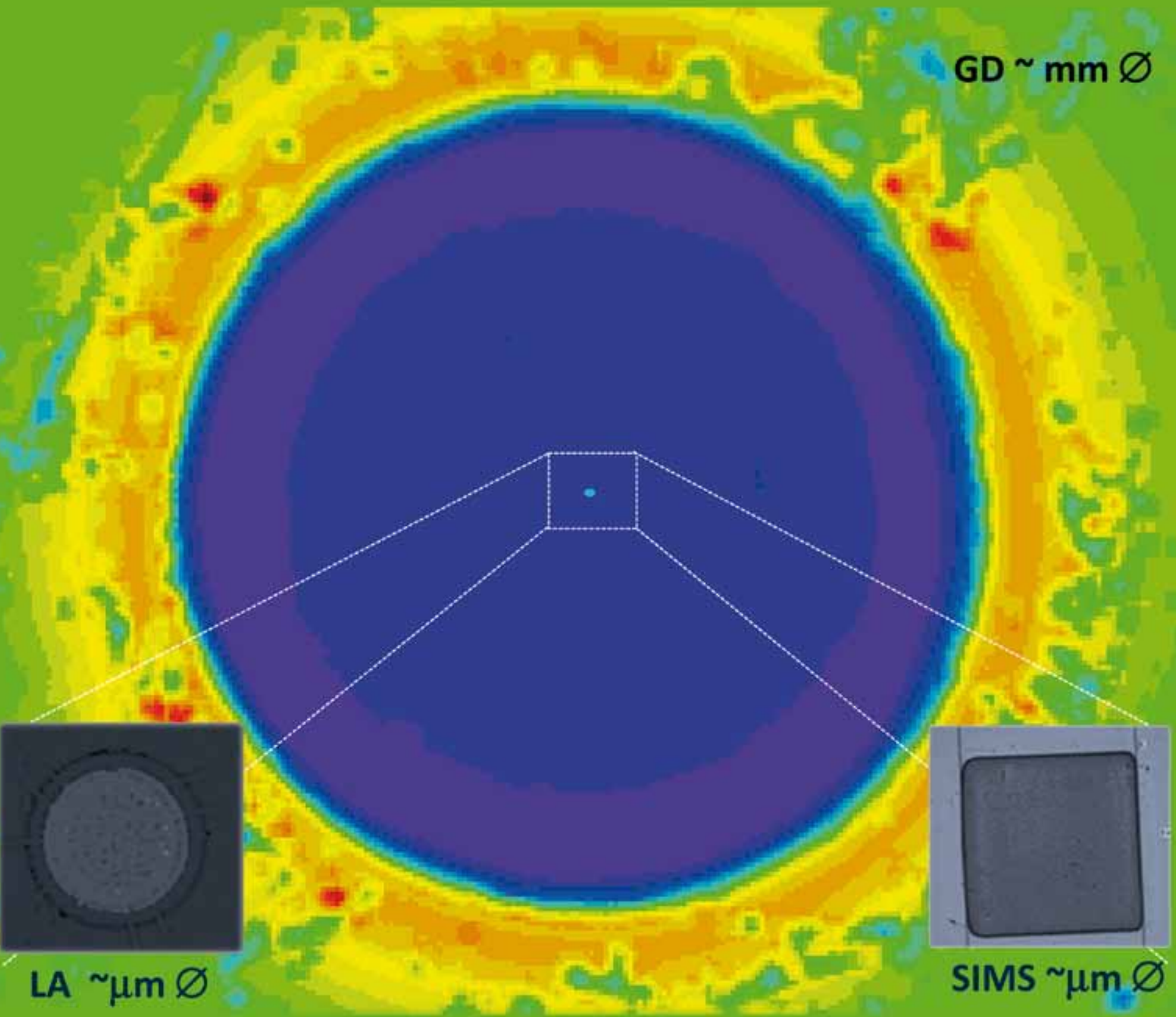

Critical Review

Pisonero et al.

Critical revision of GD-MS, LA-ICPMS and SIMS as inorganic mass

RSCPublishing spectrometric techniques for direct solid analysis

\section{Hot Paper}

Gaboardi and Humayun

Elemental fractionation during LAICP-MS analysis of silicate glasses:

implications for matrix-independent standardization
Husted et al.

Multi-elemental fingerprinting of plant tissue by semi-quantitative ICP-MS and chemometrics 


\title{
Critical revision of GD-MS, LA-ICP-MS and SIMS as inorganic mass spectrometric techniques for direct solid analysis
}

\author{
Jorge Pisonero, ${ }^{* a}$ Beatriz Fernández ${ }^{b}$ and Detlef Günther ${ }^{c}$ \\ Received 6th March 2009, Accepted 19th May 2009 \\ First published as an Advance Article on the web 8th June 2009 \\ DOI: $10.1039 / b 904698 d$
}

\begin{abstract}
Inorganic mass spectrometric techniques and methods for direct solid analysis are widely required to obtain valuable information about the multi-elemental spatial distribution of the major and trace constituents and/or isotope ratio information of a sample in a wide variety of solid specimens, including environmental wastes, biological samples, geochemical materials, coatings and semiconductors. The increasing need to characterize complex materials in industry (e.g. production control and quality assurance processes), and in different fields of science is forcing the development of various inorganic mass spectrometric methods for direct solid chemical analysis. These methods allow the characterization of solid materials both in bulk and in spatially resolved analysis (with lateral and/or indepth resolution). This review critically discusses the analytical performance, capabilities, pros and cons, and trends of laser ablation inductively coupled plasma mass spectrometry (LA-ICP-MS), secondary ion (neutral) mass spectrometry (SIMS/SNMS), and glow discharge mass spectrometry (GD-MS) because they represent the most widespread and powerful inorganic mass spectrometric methods currently further improved and applied for the direct characterization of solids.
\end{abstract}

\section{Introduction}

In many fields of industry and science, the production control and quality assurance processes are increasingly demanding fast, precise, and accurate characterization of solid specimens with high detection capabilities at high spatial resolution in order to

${ }^{a}$ Department of Physics, University of Oviedo, ClCalvo Sotelo s/n, 33007 Oviedo, Spain. E-mail: pisonerojorge@uniovi.es

${ }^{b}$ Department of Physical and Analytical Chemistry, University of Oviedo, C/Julian Claveria 8, 33006 Oviedo, Spain

'Laboratory for Inorganic Chemistry, ETH Zurich, 8093 Zurich, Switzerland achieve "total" characterization of solids at time-scales of their production. In this sense, the use of mass spectrometric methods, such as laser ablation inductively coupled plasma mass spectrometry (LA-ICP-MS), glow discharge mass spectrometry (GDMS), and secondary ion (neutral) mass spectrometry (SIMS/ SNMS), for the direct analysis of solid materials provides some unique analytical advantages. ${ }^{1-3}$ For instance, direct solid analysis techniques do not require complicated sample-preparation procedures and, also, avoid dissolution/digestion as one of the most time-consuming sample preparation procedures prior to analysis, which is associated with the risk of sample contamination, analyte loss, and the loss of spatial information.

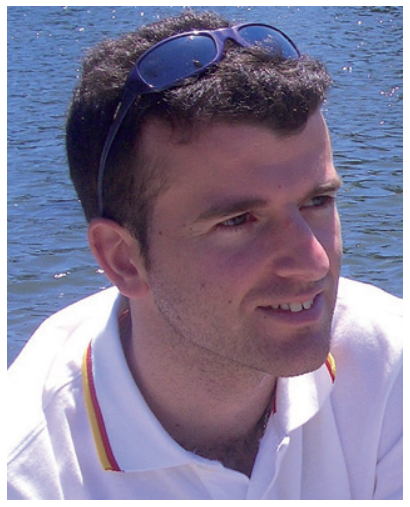

Jorge Pisonero received his PhD degree in Physics from the University of Oviedo (Spain) in 2004, for his investigations in Glow Discharge Spectroscopies (supervisors Prof. Sanz-Medel and $\mathrm{Dr}$ Bordel). He was awarded a Post-doctoral Marie Curie Intra-European Fellowship to join Prof. Günther's research group at ETH-Zürich, and to work in the field of Laser Ablation-ICP-MS. Jorge Pisonero has been Assistant Professor at the Department of Physics (University of Oviedo) since 2006. He was recently awarded a prestigious "Ramon y Cajal" Research Contract. His main scientific interests are related to plasma mass spectrometric techniques for the direct analysis of materials.

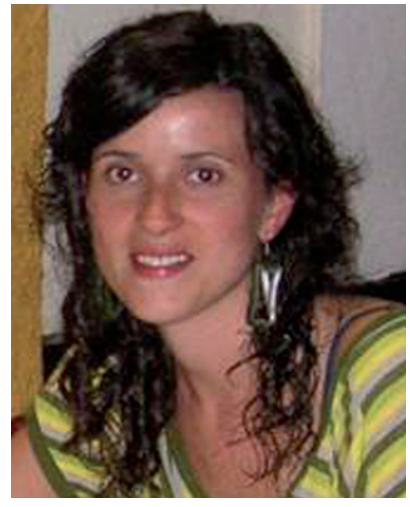

Beatriz Fernández carried out her PhD (defended in 2006) at University of Oviedo, working on the development of Methodologies based on Glow Discharges for the Analysis of Non-Conducting Materials and Liquids. Then she spent 29 months at the IPREM (Multidisciplinary Institute of Environmental Science and Materials) in Pau (France) working as a Postdoctoral Researcher on new methodologies for the analysis of trace elements in soil and sediment samples using LA-ICP-MS in combination with isotope dilution analysis. Since September 2008 she has got a three year research position at the Department of Physical and Analytical Chemistry of the University of Oviedo. 
Table 1 Summary of the processes that take place in the evaluated mass spectrometric methods

\begin{tabular}{lllcc}
\hline & GD-MS & LA-ICP-MS & SIMS & SNMS \\
\hline $\begin{array}{l}\text { Aerosol Formation } \\
\text { Atomization }\end{array}$ & $\begin{array}{c}\text { During the sputtering process } \\
\text { by discharge gas ion } \\
\text { bombardment }\end{array}$ & $\begin{array}{c}\text { Laser-induced } \\
\text { Within the inductively } \\
\text { coupled plasma }\end{array}$ & $\begin{array}{c}\text { During the sputtering process } \\
\text { by ion bombardment }\end{array}$ & $\begin{array}{c}\text { During the sputtering process } \\
\text { by ion bombardment }\end{array}$ \\
$\begin{array}{llll}\text { Within the GD plasma } \\
\text { Wonization }\end{array}$ & & & $\begin{array}{c}\text { Laser-induced or electron- } \\
\text { bombardment }\end{array}$ \\
\hline
\end{tabular}

Moreover, the use of mass analysers to separate the analyte ions provides multi-element capabilities with relatively simple spectra (most of the elements of the periodic table can be determined), isotopic information, and low limits of detection, which are the principal advantages of mass spectrometric methods in comparison to optical spectrometry techniques.

The analytical performance of inorganic mass spectrometric methods for the direct analysis of solid materials is close related to the evaporation or ablation, atomization and ionization processes, which are essential processes to generate analyte ions that will be introduced into the mass analyzer. In particular, the spatial and temporal distributions of these processes and their use as primary or secondary information have a major influence on the detection capabilities. The analyte ions can be obtained after a first evaporation/atomization step (e.g. laser-induced evaporation, or electron/ion bombardment in a glow discharge plasma) followed by an ionization step, or could be obtained by direct ionization (e.g. ionization during the sputtering process, ionization in an Ar plasma, or direct laser ionization). In this sense, it is possible to distinguish between two fundamentally different principles to generate analyte ions which are based on: i) the simultaneous evaporation/atomization and ionization processes within one step (such as in SIMS), and ii) the "postionization" (e.g. SNMS, GDMS, and LA-ICP-MS), where the evaporation/atomization processes are separated in time and space from the ionization step. Accordingly to the second principle, it is possible to optimize the sampling and ionization processes separately and, therefore, it could be concluded that these techniques provide the general possibility to be matrixindependent, resulting in a better suitability for non-matrix matched calibration approaches. ${ }^{4}$ A summary of the processes

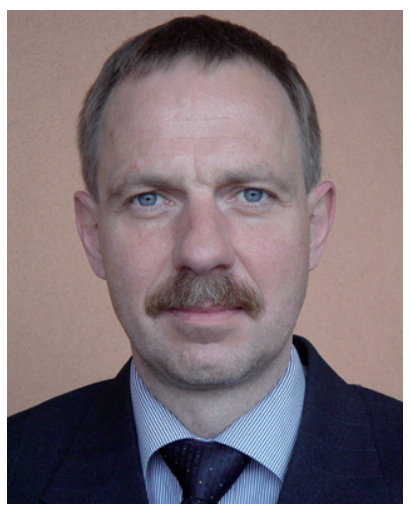

Detlef Günther is Full-Professor for Trace Element and Micro Analysis at ETH Zurich, Department of Chemistry and Applied Biosciences, Laboratory of Inorganic Chemistry. His research interests are focused on fundamental processes involved in solution nebulization and direct analysis of solids and various applications using ICP-MS and LAICP-MS. He is author and co-author of more than 210 original publications. taking place in the different mass spectrometric methods is given in Table 1.

Basically, all three inorganic mass spectrometric techniques consist of three major components: i) the ion source for the evaporation, atomization, and ionization of the sample, ii) the mass analyzer, where the ions are extracted from the ion source and are separated according to their mass to charge ratio (e.g. quadrupole (Q), time-of-flight (TOF), or double focusing magnetic sector field (SF)), and iii) the ion detection system. ${ }^{5} \mathrm{At}$ present, faraday cups and ion multipliers (e.g. Multi Channel Plate Detectors) are widely used in commercial mass spectrometers for ion detection. ${ }^{6-8}$ The type of mass analyzer used together with the different sampling and ionization sources directly influences the analytical characteristics, applications, and costs of the technique. The main differences between the mass spectrometers are their sensitivities, background intensities, and linear dynamic range (LDR). Currently, sector field-MS instruments provide the highest sensitivity and the highest linear dynamic range, between 11 to 12 orders of magnitude. ${ }^{9}$

Additionally, the mass analyzer determines the mass resolving power, which influences the capability to resolve different spectral interferences. ${ }^{10}$ Currently, sector field mass analyzers (GDSFMS and ICP-SFMS) provide a mass resolving power in the range of 3500 to $12,000 .{ }^{11}$ However, the combination of quadrupole mass analyzers together with multi-pole (hexapole, octapole, etc.) collision/reaction cells has enormously improved the analytical performance of these instruments and different polyatomic interferences that would require a much higher mass resolution can be resolved. ${ }^{12}$ Furthermore, the type of mass spectrometer determines the acquisition speed of a full mass spectrum. Whereas TOF mass spectrometers allow the simultaneous sampling and fast sequential detection of ions (20-30 $\mathrm{kHz}$ ), the acquisition speed of quadrupole and sector field mass spectrometers are limited by the number of isotopes of interest or the required magnet jumps to reach all the isotopes. Developments in sector field (fast field generator) improved the acquisition speed for transient signals, with similar capabilities as known for quadrupole instruments. ${ }^{13}$

One of the main drawbacks of most of the solid sampling techniques is the need to calibrate with solid samples of known composition. The lack of appropriate standard or certified reference materials (SRM and CRM, respectively) for a wide variety of samples of interest can restrict the accurate and precise quantitative applications of these techniques. Although qualitative and semi-quantitative analyses are very common in direct solid mass spectrometric techniques, suitable and general applicable calibration strategies for quantitative analysis remain still an unsolved challenge for a large number of samples. So far, 
different calibration strategies have been developed, including the preparation of in-house calibration samples using doped pressed powders, ${ }^{14}$ the fusion of powdered reference materials into glass, ${ }^{15}$ the direct ion implantation of a known dose of the element of interest into a matrix-matched substrate, ${ }^{16}$ etc. Nevertheless, some of these calibration strategies are not fulfilling a second requirement on reference materials, which includes the homogeneity of the elements in the solid sample or the roughness of the sample surface. The use of isotope dilution mass spectrometry (ID-MS), ${ }^{17}$ and non-matrix matched calibration approaches (solid-solid and liquid-solid) ${ }^{18}$ have been reported in the literature with promising results, but the real potential of these strategies is still under investigation. ${ }^{19}$

\section{Discussion}

\section{Laser ablation inductively coupled plasma mass spectrometry}

The combination of laser ablation (LA) technique and inductively coupled plasma mass spectrometry (LA-ICP-MS) represents one of the most modern and powerful methods for the direct determination of the elemental composition and isotope ratios in solids. Since its introduction in 1985 by $\mathrm{Gray}^{20}$ a wide variety of successful applications have been reported, especially in those fields where high spatial resolution analysis accompanied with high sensitivity is required. The fundamental principle of the LA-ICP-MS technique has remained the same over the last 24 years. A short-pulsed, high power laser beam is focused or imaged onto the sample surface in an inert gas atmosphere under normal pressure, within an airtight ablation cell. The interaction between the laser beam and the sample leads to an aerosol formation of the solid. A carrier gas flushes through the ablation cell and transports the particle-containing aerosol into the ICPMS, where it is vaporized, atomized, and ionized. ${ }^{21}$ In general, sample introduction in ICP-MS is realized using argon. In contrast, the carrier gas through the ablation cell in LA-ICP-MS has been replaced by helium due to a significant (3-5 times) enhanced particle transport, resulting in increased sensitivity. ${ }^{22}$ Specific expansion phenomena of aerosols generated by LA under helium and argon atmosphere have been observed: "vertical" expansion in helium versus "horizontal" expansion in argon. ${ }^{23,24}$ Moreover, aerosols are captured in symmetric vortices when striking a solid boundary during their kinetic stage of expansion. Only minor losses of around 1\% were observed when the aerosols got in contact with the inner walls of the ablation cells operated at atmospheric pressures.

Today's success of LA-ICP-MS in direct solid analysis is partially related to the technological progress in lasers and ICPMS instrumentation and, therefore, it should be stated that the capabilities of LA-ICP-MS depend most dominantly on the laser used for sampling with respect to the sample matrix and on the general mechanism of particle vaporization, ionization and ion sampling within an ICP. Therefore, no generally applicable protocols can be suggested for the wide variety of samples that are currently investigated by means of LA-ICP-MS.

General capabilities. LA-ICP-MS allows trace and ultra trace element analysis at high lateral and depth resolution (few $\mu \mathrm{m}$ and hundreds of nm, respectively). ${ }^{25,26}$ Moreover, the sampling process is not limited to the physical and chemical properties of the materials of interest and, therefore, a wide variety of samples such as conducting, non-conducting, hard, soft, and coated solids can be directly analyzed. ${ }^{27-30}$ All the samples just need to fulfil one general requirement; they must be kept in a stable form (e.g. solid or pressed powder and dry or cooled-frozen $)^{31}$ For instance, LAICP-MS has been applied as a spectrochemical technique for provenance and forensic studies (e.g., the chemical analysis of debris found at crime scenes and on the clothes of suspects). ${ }^{32}$ In this sense, international collaborations (e.g., the European Unionfunded global network on Natural Isotopes and Trace Elements in Criminalistics and Environmental Forensics (NITE-CRIME)) ${ }^{33}$ are highly required to develop approved and tested analytical methods, which could be used in front of the court of law. In particular, the main objective of the NITE-CRIME interlaboratory tests was to cross-validate the different combinations of laser ablation systems with different ICP-MS instruments. ${ }^{34}$ Extensive discussion among the laboratories and the production of new glass reference standards established an improved analytical protocol, demonstrating that LA-ICP-MS can deliver absolute quantitative measurements on major, minor and trace elements in float glass samples for forensic and other purposes.

Quantitative analysis can be realized using an external standard (e.g. using matrix-matched and non-matrix matched calibrations). ${ }^{35}$ Furthermore, although the ablation rate is matrix-dependent and, therefore, requires an internal standard, ${ }^{36}$ alternative quantification strategies, where all matrix elements are used for internal standardization, have been recently reported. ${ }^{37,38}$ On the other hand, it is well known that limits of detection in LA-ICP-MS are a function of background signal, counting time per element, and sensitivity; this latter depending on the amount of ablated material (i.e., on the spot size, laser energy and laser frequency). For instance, a simple, rapid and sensitive method has been recently developed for the routine analysis of trace elements on sediments and soils by ultraviolet ns-LA-ICP-MS. ${ }^{39}$ In particular, two independent proficiency tests for trace metals in soils were conducted to compare the performance of the method versus conventional digestion ICP and Atomic Absorption methods. An overall bias between 8 and $15 \%$ was found, depending on the sample, while the overall precision was found to be better than $5 \%$ RSD for all samples. Limits of detection were as low as $0.01 \mathrm{mg} \mathrm{kg}^{-1}$.

The precision of LA-ICP-MS measurements is mainly dominated by the concentration of the analyte in the sample, as well as, by its heterogeneity within the sample and within the standards, in relationship to the internal standard. ${ }^{40,41}$ Accuracy in LA-ICP-MS depends on precision and on all other parameters of aerosol sampling, aerosol transport, and aerosol excitation. Most commonly LA-ICP-MS measurements are compared to bulk analysis, which made the validation of this technique difficult, and a general value for the accuracy obtained by LA-ICPMS cannot be given. In addition, it could be stated that the major limitation in terms of accuracy and precision in LA-ICP-MS is given by the standard reference materials which are mainly certified using bulk techniques and, therefore, are not necessarily homogeneous on the micro-scale. ${ }^{42,43}$

Critical comments on LA-ICP-MS. One of the main limitations of LA-ICP-MS, and basically of all laser-based sampling 
techniques, is the occurrence of non-stoichiometric effects in the transient signals, defined as elemental fractionation. ${ }^{44}$ All processes involved in LA-ICP-MS (the aerosol formation process, the transport of the aerosol into the ICP, and the conversion of the aerosol into ions within the ICP may potentially alter the stoichiometric composition of the laser-generated aerosol depending on the chemical and physical properties of the elements, resulting in unknown contributions to elemental or isotopic fractionation effects. ${ }^{6,45,46}$ Fig. 1 shows a schematic overview of the interactive parameters in LA-ICP-MS and their influence on quantitative analysis. The "Golden rules" summarize the suggested optimum conditions as a function of the type of material being analyzed. ${ }^{4}$

Three different types of laser-induced fractionation have been described for laser ablation: i) fractionation through preferential evaporation of volatile elements into the carrier gas, ${ }^{47}$ ii) particlesize-related elemental fractionation, ${ }^{48}$ and iii) laser-induced isotopic fractionation. ${ }^{49}$ Therefore, there are several reasons for elemental and isotopic fractionation effects (e.g. preferential vaporization of elements (or isotopes) from the sample, failure of large particles to be transported to the ICP, or incomplete vaporization of large particles that manage to reach the ICP source). Additionally, since all processes are successive and resulting in one signal their individual contributions are difficult to distinguish.

The experimental parameters used for the LA process determine the amount, the composition, and the particle-size distribution of the aerosol released for a given sample, so the influence of such parameters has been widely investigated in recent years to better understand and to minimize the limitations of LA-ICPMS. ${ }^{50}$ Most of the work carried out so far has been focused on the wavelengths related sampling process (infrared versus ultraviolet wavelengths), the pulse duration (nanosecond versus femtosecond LA), the LA carrier gas (Ar versus $\mathrm{He}$ or $\mathrm{Ne}$ ), and the LA cell design, as significant parameters that play important roles in aerosol formation. ${ }^{4}$ Although no significant changes have

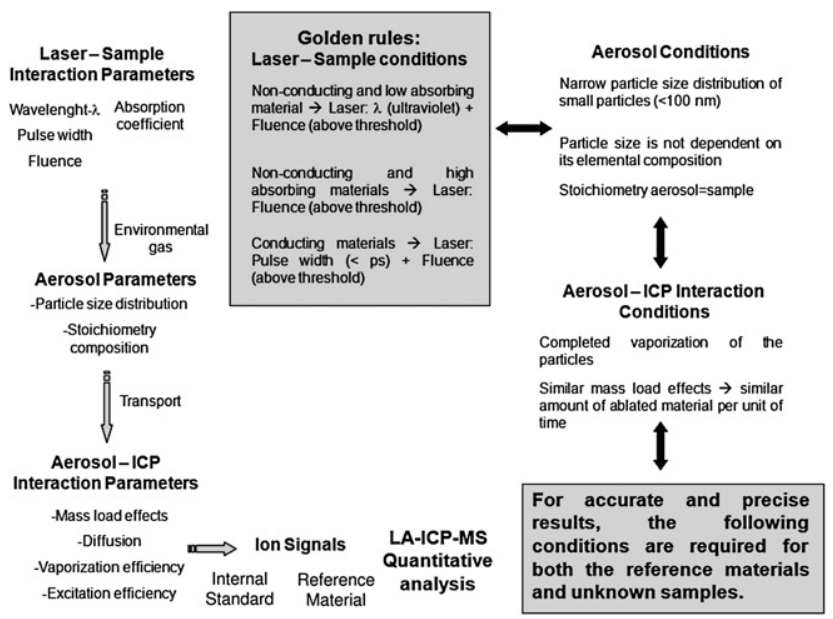

Fig. 1 Schematic overview of the interactive parameters in LA-ICP-MS and their influence on quantitative analysis. The "Golden rules" summarize the suggested optimum conditions as a function of the type of material being analyzed (reprinted with permission from Mass Spectrometry Reviews, 2008, 27, 609). been made on the well-established ICP source, new instrumental developments both on the MS and on the laser side always yield new insights and applications. The developments performed in the laser area have mainly been driven in two directions: shorter wavelengths and shorter pulses. ${ }^{51,52}$ Both aimed at unifying the idea of more efficient and defined use of the laser-pulse energy delivered onto the sample for stoichiometric aerosol generation.

The proper choice of laser parameters such as the fluence (laser energy per unit area), pulse duration, and wavelength are defining the size, the size distribution, and the composition of the ablated particles. ${ }^{53,54}$ For instance, conditions for non-matrix matched calibration prevail if LA is accomplished within a fluence range that favours the convergence of elemental ratios to asymptotic values. These conditions are achieved for fluences well above the material dependent threshold of LA. Fig. 2 shows a ${ }^{66} \mathrm{Zn} /{ }^{65} \mathrm{Cu}$-, and ${ }^{208} \mathrm{~Pb} /{ }^{65} \mathrm{Cu}$-specific calibration study on glass and brass samples using an ultraviolet-femtosecond-LA-ICPMS system. Deviation of measured and theoretical ratio values were found to continuously drop within the medium and high fluence range, eventually falling below 40 and $5 \%$, respectively. ${ }^{28}$

We next present a detailed description of the most relevant parameters governing the quality of analysis as well as several applications to illustrate the performances and limitations in LA-ICP-MS analysis.

Particle-size distribution and fractionation effects. Knowledge about aerosol particle sizes in laser-generated aerosols and fundamental understanding of aerosol formation and particle transport are important aspects to better understand and improve LA-ICP-MS analysis. Analytical performance of laser ablation using ICP-MS detection is significantly influenced by the particle size distribution of the generated aerosol since the chemical composition, transport efficiency and decomposition of the aerosol within the ICP are closely related to the size of the aerosol particles. For instance, full vaporization or ionization within the ICP can not be achieved for particles bigger than a certain critical size which depends on the material. ${ }^{5-57}$ As has been widely reported, the thermal character of the laser ablation

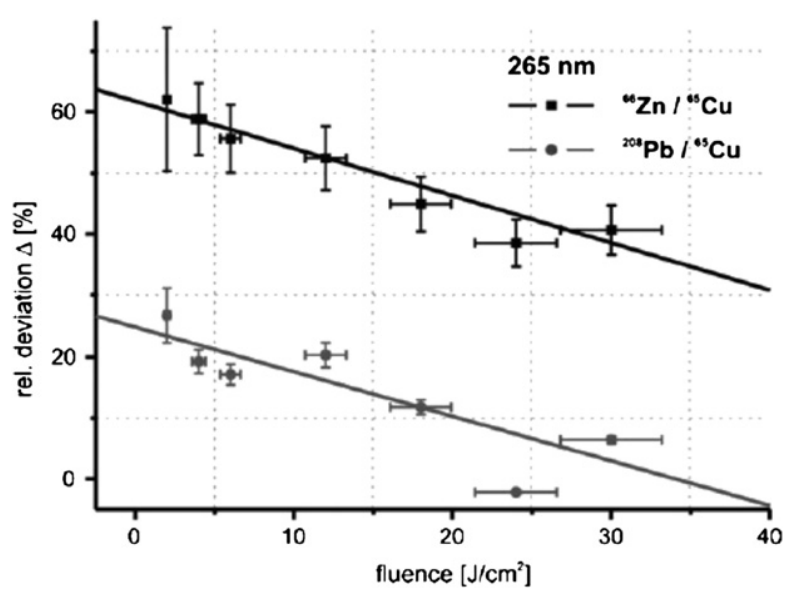

Fig. 2 Deviation of theoretical and experimental ratio values of ${ }^{6} \mathrm{Zn} /{ }^{65} \mathrm{Cu}$ and ${ }^{208} \mathrm{~Pb} /{ }^{65} \mathrm{Cu}$, measured on brass and glass samples using an UV-fs-LA-ICPMS system at different laser fluences (reprinted with permission from J. Anal. At. Spectrom., 2006, 21, 932). 
process might lead to the formation of agglomerates and molten spherical particles of different sizes (broad particle size distribution $)^{58-60}$ in dependence on the wavelength. ${ }^{61}$ For instance, in the case of silicate and oxide samples, higher absorptivity of the sample and smaller particles of the induced aerosol are obtained using shorter wavelengths (e.g. ultraviolet-LA). The utilization of femtosecond laser pulses probably represents the most promising instrumental advancement to enable the production of ultra-fine aerosol particles from a wide variety of samples. For instance, fs-LA of brass was found to produce larger agglomerates composed of small and narrowly distributed particle sizes, time ns-LA generated a wide range of particle as large as several micrometers in diameter. ${ }^{53}$ How much wavelength dependence remain for fs lasers is currently unknown on a wide variety of samples with different absorption behaviours.

Typical laser ablation systems with pulse durations of a few nanoseconds (e.g. Nd:YAG $(\sim 5 \mathrm{~ns})$ and $\operatorname{ArF}$ excimer $(\sim 15 \mathrm{~ns})$ lasers) promote the formation of a so-called "heat-affected zone" around the laser spot, which is caused by thermal diffusion into the solid sample. As a consequence, fractionation effects due to material redistribution can take place even if the local temperature accumulated during the laser-matter interaction is intense enough to evaporate the most refractory elements. In contrast to ns laser systems, during femtosecond laser ablation the pulse duration falls below the thermal relaxation time $(\sim 10 \mathrm{ps}),{ }^{62}$ which is the time needed to transfer the absorbed pulse energy from heated electrons to the lattice, thus, reducing thermal effects even for materials with high thermal diffusivity. This means that the affected material is fully removed with no or minimal damage to the surrounding area. Therefore, fs-laser sampling is able to provide chemical information with high spatial resolution and sensitivity. ${ }^{26}$ However, a pure comparison of thermal relaxation times does not take into account the correlation of heat diffusion and evaporation rate of molten material, which was recently found to be strongly fluencedependent. ${ }^{63}$

Additionally to the pulse duration, the laser wavelength and fluence determine the ablation rate, and these parameters are difficult to separate in their contributions to fractionation effects. The use of shorter wavelengths (changing from visible and infrared to today's dominant ultraviolet wavelengths such as 266 $\mathrm{nm}, 213 \mathrm{~nm}$, and $193 \mathrm{~nm})^{28,64}$ and the use of shorter pulse durations (changing from ns to fs), represent the most promising instrumental advancements due to their demonstrated advantages in the LA behaviour. ${ }^{50,65}$ On the other hand, it should be stated that the optimum value for the laser energy per unit area can significantly change depending on the sample of interest. In this sense, Koch et al. ${ }^{66}$ investigated the analysis of multicomponent silicate glasses by fs-LA-ICP-MS showing that stoichiometric aerosols for opaque glasses can be obtained in a fluence range above $5 \mathrm{~J} / \mathrm{cm}^{2}$ while fluences below $5 \mathrm{~J} / \mathrm{cm}^{2}$ usually resulted in stronger differences from the bulk composition (indicating intensified fractionation during the LA process). Nevertheless, in contrast to the analysis of dielectric samples, a fluence value of about $5 \mathrm{~J} / \mathrm{cm}^{2}$ should not be exceeded for the analysis of metallic specimens, due to the occurrence of intensified production of $\mu \mathrm{m}$ particles and, consequently, the presence of elemental fractionation effect. ${ }^{54}$ Therefore, it could be concluded that careful optimization of experimental conditions will be necessary in every specific application to obtain accurate and precise results.

Matrix effects. The existence of a significant matrix effect depending on the mass load of the ICP is another source of fractionation in LA-ICP-MS that should be considered in the quantification procedure. Kroslakova and Günther ${ }^{67}$ have recently demonstrated that the mass load enhanced matrix effect is element dependent and most severe for elements with low boiling points (e.g. $\mathrm{Cu}, \mathrm{Zn}, \mathrm{Ag}, \mathrm{Cd}$, and $\mathrm{Pb}$ ). The induction of matrix effects independently of the ablation process indicated that elements $(\mathrm{Cu}, \mathrm{Zn}, \mathrm{Cd}, \mathrm{Pb}$, and $\mathrm{U})$, previously described to be dominantly influenced by laser-induced elemental fractionation, undergo significant ICP-induced matrix effects. These matrix effects were mass load dependent and for most elements exceed the contribution of laser-induced fractionation. Moreover, although it was shown that matrix effects become less severe using aerosol dilution, it should be emphasized that the order of magnitude of such effects might differ from matrix to matrix.

Similarly, the vaporization and ion generation of different elements (in elemental form and as oxides) takes place in different zones of the plasma, even for a narrow and small particle size distribution. As a consequence, the ion sampling efficiency will then also be different for various mass loads. This fact is more critical in LA-ICP-MS because this technique commonly relies on one internal standard, which is not suitable for correcting mass load dependent matrix effects as well as the element dependent ion sampling efficiency into the mass spectrometer, especially when ions are generated within different zones of the plasma. Therefore, accurate quantitative analysis by LA-ICP-MS can only be carried out by using the same crater diameters and ablation times for the standards and the samples. Furthermore, it needs to be mentioned that a similar absorptivity of the sample of interest and the standards will not only provide a similar particle size distribution, but also a similar mass load of the plasma.

Calibration strategies. Recent applications of fs-LA-ICP-MS pointed the analytical characteristics and excellent capabilities of this technique for quantitative analysis of different solid matrices (e.g. brass, stainless steel, aluminium, and silicate glasses). ${ }^{27,35,68}$ Matrix and non-matrix matched quantitative analysis showed that improved analytical performance in terms of precision and accuracy was achieved using shorter laser-pulse durations. Although the use of silicate reference materials as calibration standards has proved in the past to be a feasible way of quantification for a wide variety of matrices, especially oxides, ${ }^{69,70}$ different calibration strategies are currently being investigated to enable multi-matrix calibrations with adequate accuracy using ultra-fast femtosecond laser pulses and ultraviolet wavelengths. ${ }^{35,28}$ Additionally, it should be stressed that the use of isotope dilution mass spectrometry in combination with LAICP-MS allows the accurate, precise, and time-effective quantitative analysis of trace elements in powdered samples using different isotope dilution calibration strategies (e.g. on-line ${ }^{71}$ solid-spiking, ${ }^{72,73}$ and in-cell ${ }^{74}$ isotope dilution analysis). In contrast to other calibration procedures, if a homogeneous distribution of both isotopically enriched spike and analyte is achieved, the analytical results are not affected by signal drifts, 
matrix effects, or analyte losses and, thus, the application of isotope dilution in LA-ICP-MS can correct for some common fractionation and matrix effects that cannot be controlled using other calibration strategies. Drawbacks associated to the use of isotopic dilution methods include the high price of the spikes and the non-applicability of this method to all the elements.

Depth-profiling analysis. Depth profile resolution is generally affected by the shape of the craters produced by laser ablation. Non-uniform crater shapes (convex or concave bottoms), which are usually produced by a non-completely homogenized laser beam, and strong laser-induced surface roughness result in a limited depth resolution due to the fact that sample material from different layers can be simultaneously ablated. ${ }^{26,4}$ Moreover, the depth resolution of real LA-ICP-MS systems is also limited by the pulse mixing and signal tailing induced by the aerosol transportation (sample material originating from different depths will enter the plasma simultaneously). ${ }^{75}$ In this sense, it could be stated that the use of low volume ablation cells is crucial to provide optimum signal to background ratios. Recently, the capabilities of UV-fs-LA-ICP-MS have been demonstrated for high (sub-micrometer) depth resolution, tested on thin metal coatings. ${ }^{25}$ The use of low laser fluences $\left(0.4 \mathrm{~J} / \mathrm{cm}^{2}\right)$ together with a low laser repetition rate $(1 \mathrm{~Hz})$ was found to provide very small ablation rates $(<6 \mathrm{~nm} /$ pulse), which corresponded to only 60 atomic layers per shot. Additionally, the fast ion signal decay obtained with a special low volume ablation cell (HEAD cell) ${ }^{76}$ indicated that the transport system plays a minor role in limiting the depth profiling capabilities, whereas the degradation of depth resolution was mainly related to the formation of non-ideal concave craters caused by a non-uniform (Gaussian) laser beam profile.

Another limitation preventing accurate and precise depth profile analysis is the element-selective, non-reproducible ablation. It has been observed that elemental fractionation becomes significant for some elements (e.g., $\mathrm{Zn}, \mathrm{Pb})$ when the depth $(>200$ $\mu \mathrm{m}) /$ diameter ratio of the ablation crater is $>6 .{ }^{77}$

Trends. As has been previously reported, in order to reduce fractionation effects, a narrow particle size distribution for the laser-generated aerosol is strongly required and, also, the aerosol composition should represent the stoichiometric composition of the sample. State-of-the-art fs-LA exhibits excellent analytical performance in comparison with ns-LA, as fs-LA provides accurate and precise results in a wide range of applications, not only in geological and material sciences but also in some further specific fields (e.g. biological and medical applications). ${ }^{27,78,79}$ The use of fs laser radiation allows the direct analysis of solid samples with a less laser-induced elemental fractionation although, as has been reported by Koch and Günther, ${ }^{80}$ minor variations of the small flow of material $(\sim \mathrm{ng} / \mathrm{s})$ into the ICP could induce mass load matrix effects, which might result in inaccurate quantifications. Therefore, fs-LA without considering the wavelength effects on particle size distribution for a wide variety of differently absorbing matrices, further studies on aerosol expansion, and further investigations on the role of agglomerates in the vaporization efficiency within the ICP, will not be the solution for accurate analysis. Furthermore, the ICP itself remains an unsolved problem when introducing micro- or

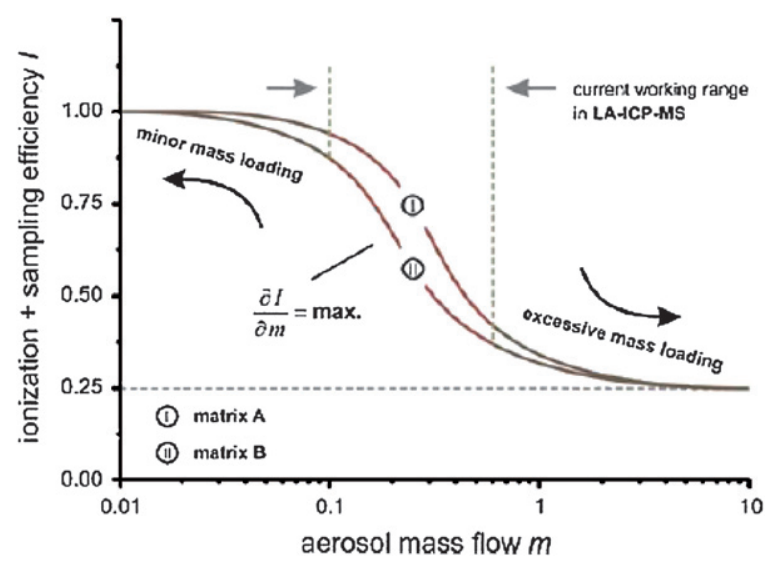

Fig. 3 Schematic representation of the influence of matrix and aerosol mass flow on the element-specific ionization efficiency of the ICP. Vertical dashed lines indicate the current working range of LA-ICP-MS (Reprinted with permission from Anal. Bioanal. Chem., 2007, 387, 149).

nano-particles. The vaporization efficiency in dependence on particle size, composition, and residence time with respect to the position of completeness, will be most important for congruent ion sampling. As long as particles will not behave completely like micro-droplets, LA-ICP-MS will remain matrix dependent. It has been suggested that in order to overcome this problem, we need to push the working range of LA-ICP-MS to stationary conditions by either minor or excessive mass loading (see Fig. 3), making use of low-energy laser ablation, aerosol dilution, or supplementary entrainment of aspirated liquids ${ }^{80}$ In particular, excessive mass loading based on simultaneous liquid aspiration (wet plasma) can help to perform more reliable analyses of laserproduced aerosols, but at the expense of an increased oxide formation rate and polyatomic interferences ${ }^{81}$ Moreover, recent modelling studies using advanced computational fluid dynamics techniques could be considered as a promising approach to improve LA-ICP-MS analytical performance. ${ }^{82-84}$

\section{Glow discharge mass spectrometry}

Glow discharge (GD) analytical plasmas have gained importance as atomization and ionization sources for mass spectrometry (MS) due to the capability of these low-pressure plasmas to generate ionic populations directly from the solid samples. ${ }^{85} \mathrm{~A}$ GD plasma is initiated when applying a high potential $(\sim \mathrm{kV})$ between two electrodes containing a discharge gas (usually pure noble gases such as $\mathrm{Ar}$ and $\mathrm{He}$ ). The discharge gas is electrically broken down to form electrons and positive ions which are accelerated towards the cathode surface. Release of cathode material into the gas phase (sputtering process) is achieved due to the bombardment of the cathode surface by positive ions and fast atoms with sufficient energy. The sputtered material may follow an extensive list of collisional processes in the plasma, highlighting collisions with energetic electrons (electron excitation and ionization), collisions with discharge gas metastable species (Penning ionization and excitation) and collision with discharge gas ions (Asymmetric charge transfer). ${ }^{86,87}$ The most common mode of operation in GD spectrometry is the application of a direct current (dc) voltage, as it has been demonstrated to be 
a rapid and easy-to-handle technique for the elemental analysis of electrically conducting samples. ${ }^{\mathbf{8}}$ Nevertheless, the increased use of radiofrequency ( $\mathrm{rf}$ ) powered glow discharges has broadened GD applications to the analysis of non-conductive samples due to their ability to sputter both conducting and insulating materials. ${ }^{89}$ The atomization and ionization processes in GD are separated in space and time, resulting in only minor variations in relative sensitivities, and in little matrix dependence, so quantification is possible without the absolute need for matrix-matched standards. Moreover, GD-MS is a valid concept as it embraces the speed of GD-Optical Emission Spectroscopy (OES) with the exceptional MS detection capabilities (including isotopic information).

General capabilities. The application of glow discharge devices as primary spectrochemical sources for direct solid elemental analysis in mass spectrometry is increasing because they offer several important advantages, such as a high depth resolution $(\sim \mathrm{nm})$, fast sputtering rate (in the order of $\mu \mathrm{m} / \mathrm{min}$ ), multielement capabilities (most of the elements of the periodic table can be determined), isotopic information in a relatively simple spectrum, low matrix effects, low limits of detection (in the range of $\mu \mathrm{g} / \mathrm{g}-\mathrm{ng} / \mathrm{g}$ ), and ease of use. The significant features of rf-GDMS for depth-profiling analysis of coatings arise from the nature of the sputtering mechanism in rf-GD, in which solid samples are stably and reproducibly sputtered with $\mathrm{Ar}^{+}$ions of very low energy $(<50 \mathrm{eV}){ }^{88} \mathrm{The}$ low $\mathrm{Ar}^{+}$energies ensures that sputtering proceeds without significant formation of altered layers, a very important pre-requisite for successful depth profiling analysis of thin films at high depth resolution. ${ }^{90-92}$ Additionally the development of modified Grimm-type GD ion sources for the analysis of flat samples allows a high sample throughput. ${ }^{93}$ After sample changing, the source is evacuated by a pump in less than a minute, so the sample can be changed easily and rapidly. Moreover, the cleaning process of the source is simple and can be performed from the atmospheric-pressure side of the source.

Pulsed dc/rf GD-MS. The use of pulsed $\mathrm{rf} / \mathrm{dc}$ GD sources offer a real possibility for separating elemental and molecular excitations due to the temporal distribution of power (with time domains called pre-peak, plateau, and afterglow). ${ }^{94}$ The pulsed mode gives high instantaneous power, increasing the atomization, excitation, and ionization processes without inducing thermal degradation of the sample, which is really beneficial for sensitive materials. ${ }^{95-97}$ Pulsed-GD-MS shows an important niche of applications, including the analysis of different metals in the trace element range, ${ }^{98}$ analysis of non-conducting solids (e.g. ceramics, glasses, and polymers), ${ }^{99}$ and analysis of coatings and thin films with high depth resolution. ${ }^{6}$ For instance, Fig. 4 shows molecular depth profiles of thin polymer films on silicon substrates, ${ }^{100}$ and Fig. 5 shows a qualitative depth profile of an ultra-thin $\mathrm{Cr}$-delta layer $(2 \mathrm{~nm})$ embedded in a thin alumina coating. ${ }^{6}$

\section{Critical comments on GD-MS}

Adequate crater shapes for depth profiling. Crater shapes with a flat bottom and walls perpendicular to it are required to obtain a high depth resolution in the analysis of coatings and thin films. Nevertheless, optimum operating conditions to obtain adequate crater shapes do not usually match the optimum conditions to obtain the maximum sensitivity, thus, a compromise should be considered. The characteristics of the crater shape depend on the electric characteristics of the GD, such as the electrical potential distribution in front of the cathode, which is influenced by the gas flow distribution, the density and energy distribution of the species bombarding the cathode, and the re-deposition of sputtered atoms at the cathode surface. ${ }^{101}$ These parameters are closely related to the ion source design. In this sense, modelling of the ion source has been used to study and optimize the operating conditions in order to obtain a uniform sputtering rate over the complete crater area. ${ }^{102}$ Furthermore, gas flow rate patterns are of special importance in GD-MS because of their influence on ion transport to the mass spectrometer. The special requirements for the discharge gas flow could disturb the crater shape producing crater profiles similar to that obtained with the socalled jet-enhanced sources. ${ }^{103}$ Temperatures of the cathode, anode, and discharge gas, which are related to the secondary electron emission yield, have also a strong influence on the GD-MS results and they are often not known with accuracy.

Sample requirements. Although glow discharge sources can offer depth profiling analysis with an excellent depth resolution, one of the major limitations of this technique is the limited lateral resolution. GD ion sources show restricted lateral resolutions in the order of $1-8 \mathrm{~mm},{ }^{104}$ which are directly related to the size of the sampling orifice. Therefore, solid samples have to fulfil specific requirements on shape and dimensions. For instance, non-flat samples (e.g. screws and tubes) are not suitable for direct mounting on the GD source and require the development of special fixing tools. Moreover, porous materials, such as foams and certain ceramics, are difficult to handle because they are not vacuum tight (usually the sample is used to seal the GD source).

Influence of small amounts of reactive impurities. The presence of reactive impurities (e.g. hydrogen, nitrogen, or water vapour) coming from the discharge gas, the GD source, or directly from the sample, has been observed to have a large effect on the ion production and sputtering rates in GD-MS analyses. ${ }^{105,106}$ It has been reported that the sample sputtering rates decreased when hydrogen was added to the discharge in spite of working at constant applied electrical conditions. ${ }^{107}$ Moreover, the ion intensities for the different species present in the discharge were enhanced at increasing hydrogen concentrations up to $10 \%$. Similar studies have demonstrated that $\mathrm{Ar}+\mathrm{H}_{2}$ spectra show a severe, but selective, quenching of the ionization. ${ }^{108}$ In addition, a common trend with nitrogen and oxygen addition is the significant loss of the Ar and ArH ion signals. ${ }^{109}$ Thus, it should be stated that the presence of reactive gases has to be seriously taken into account in the quantification process (e.g. using different corrections for the light elements). Such gases might be able to produce serious alterations to the excitation and ionization mechanisms in the GD plasma and, hence, to the analytical signals.

Absolute and relative sensitivity factors for quantification. The low matrix dependence of GD-MS in comparison with other solid state analytical techniques provides absolute sensitivity factors which are matrix independent in a first approximation. 

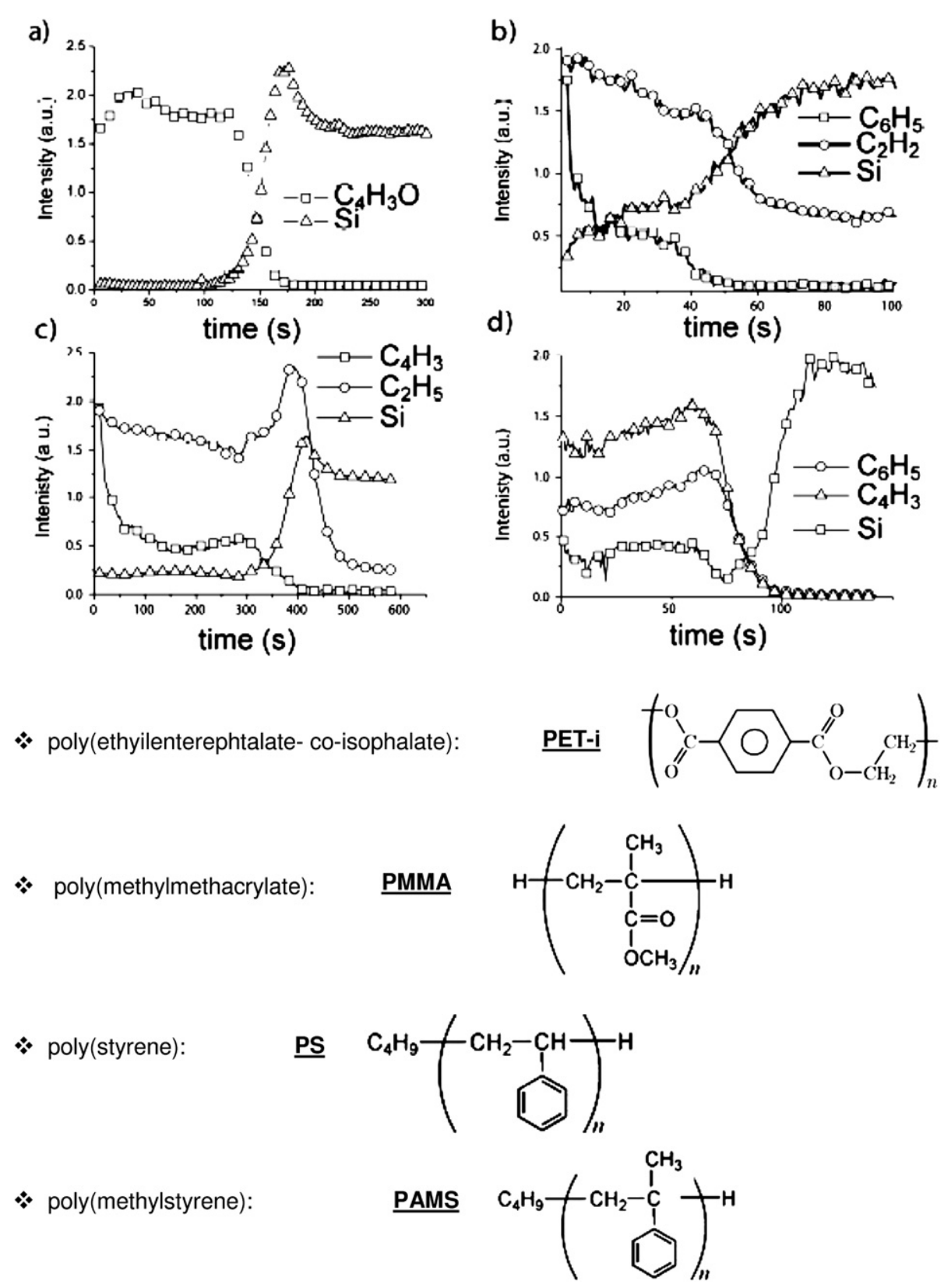

Fig. 4 Typical pulsed-rf-GD-MS molecular depth profiles of thin (200 nm) polymer films, a) PMMA, b) PS c) PETi d) PAMS, on silicon substrates (reprinted with permission from Rapid Communications in Mass Spectrom., 2009, 23, 549).

The absolute sensitivity factor of an isotope considers the ionization yield, the ion transport yield and the instrumental parameters that affect the ion signal. This factor is calculated for each isotope as the inverse of the slope of the calibration curve (ion signal intensity versus content of the isotope in the sample multiplied by the sputtering rate). Depth profile quantification of conductive zinc coatings has been reported for GD-MS using multi-matrix calibrations, due to the low matrix dependence. ${ }^{\mathbf{1 1 0}}$ Morevoer, comparison of certified values of different reference materials with the measured values based on calibrations with pressed powder samples led to deviations less than $30 \%$ for most of the considered examples. ${ }^{111}$ Usually, isotope absolute sensitivity factors are normalized to that of an internal standard isotope in order to obtain the relative sensitivity factors
(RSFs). ${ }^{112,113}$ Using this concept, the quantitative results in stainless steel agreed with the certified values and showed fine precision, for example R.S.D. of most elements were less than $3 \%$, except several low content elements. ${ }^{114}$ Nevertheless, the need to perform quantitative analyses by GD-MS with a higher accuracy still requires the determination of matrix-matched element-specific RSF, whenever suitable reference materials are available. Additionally, the models and methods used to compute quantitative depth profiles by GD-MS are at a primitive stage in comparison to those developed for GD-OES analyses.

Coupling the GD to different mass analysers. Concerning the coupling of GD sources to different types of mass analyzers, it needs to be highlighted that the use of sector field and 

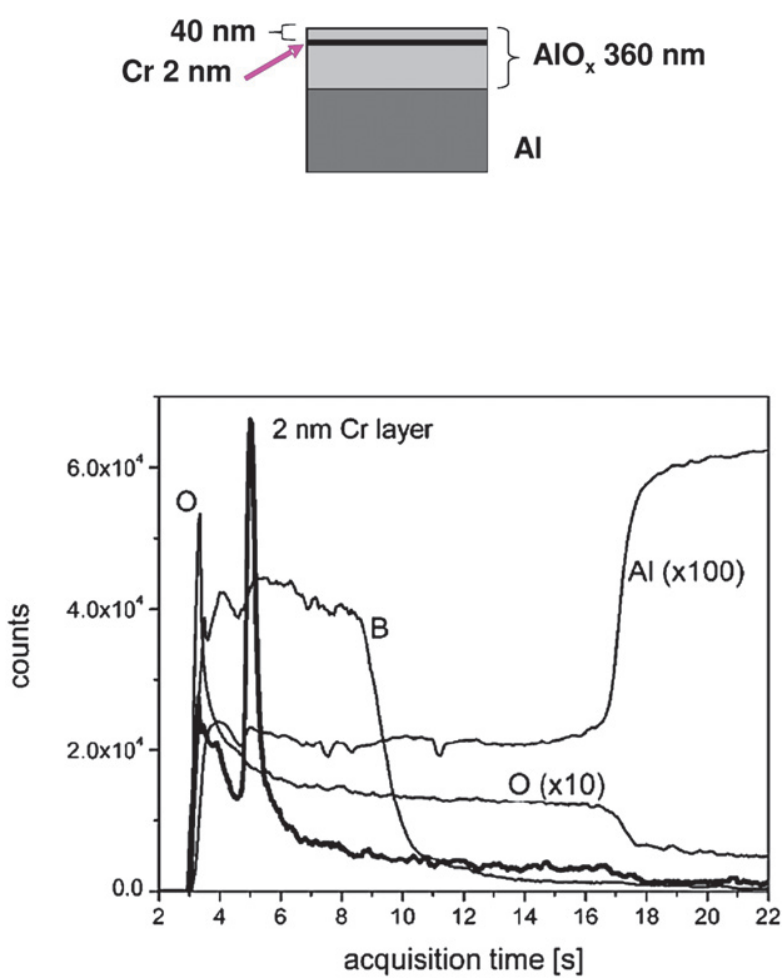

Fig. 5 Pulsed-rf-GD-MS qualitative depth profile of ultra-thin Cr-delta layer $(2 \mathrm{~nm})$ embedded at $40 \mathrm{~nm}$ from the surface of a thin alumina coating (reprinted with permission from Surf. Interface Anal., 2006, 38, 292).

time-of-flight mass analyzers increased continuously during the last years. GD-SFMS provides low limits of detection ( $\sim p p b)$ and high mass resolution (up to 10.000), and helps to overcome problems of molecular species formed in the plasma which can appear at the same nominal mass as the peaks of interest. Nevertheless, the fact that all GD-SFMS systems are sequential in nature is a serious limitation for the analysis of fast signals (e.g. depth profiling studies). The number of elements that can be monitored effectively is related to the duration of the transient signal (e.g. related to the thickness of the coating and sputtering rate). GD-SFMS instruments are currently the only GD-MS commercially available and are manufactured by Thermo Fischer Scientific with a fast-flow Grimm-type GD cell.

Alternatively, time-of-flight (TOF) mass analyzers offer many interesting features: (i) quasi-simultaneous detection of a large mass range, from hydrogen to macro-molecules, ${ }^{115}$ (ii) higher mass resolving power compared to a quadrupole $\mathrm{MS},{ }^{116}$ (iii) lower cost compared to high resolution SFMS and (iv) high spectral acquisition rate that allows the measurement of transient ion signals. ${ }^{117}$ Taking into account these unique properties of time-of-flight mass analyzers, the use of GD-TOFMS offers great potential in the area of depth profiling analysis, especially for thin layers where the composition of the sample changes rapidly with time and the quasi-simultaneous multi-analyte determination of many isotopes should be carried out at every sample depth. ${ }^{118}$ However, the restricted sensitivity, dynamic range and mass resolution of GD-TOFMS systems limit the detection limits. The mass resolving power in the TOFMS could be improved up to 5000 to overcome most of the $\mathrm{H}, \mathrm{C}, \mathrm{O}$ and $\mathrm{Ar}$ interferences using the $\mathrm{W}$ mode (use of two reflection lenses); however, the sensitivity is further reduced by at least one order of magnitude.

Trends. Further development of radiofrequency sources as well as the use of "fast flow" high powered sources is being currently investigated to improve the analytical capabilities of GD-MS and the sample throughput. ${ }^{119}$ The use of a fast flowing glow discharge ion source allows high current, power, and sputtering rate, increasing the intensity of the analytes and their ratio to the water-derived ions. ${ }^{\mathbf{1 0 8 , 1 2 0}}$ Moreover, the analytical potential of modulated radiofrequency GD-TOFMS provides a unique "multi-dimensional" analysis tool, allowing simultaneous elemental and molecular quantification, with low sensitivity $(<\mathrm{ppm}$ ) and high depth resolution (below $5 \mathrm{~nm}$ ) in conductive and non-conductive thin layers, for most of the elements of the periodic table. Although some investigations have been previously conducted using a pulsed dc-GD coupled to a TOF mass analyzer, ${ }^{121,122}$ it has been observed that pulsed dc-GD considerably fragments the molecules, reducing the efficiency to obtain molecular information. Finally, it needs to be highlighted that a novel chemical ionization source based on GDs has been recently reported by Andrade et al. ${ }^{123,124}$ for organic mass spectrometry. This new source uses a glow discharge in the flowing afterglow mode for the generation of excited species and ions, and can be considered as another new technique in the field of ambient mass spectrometry. The species generated by this atmospheric pressure GD are mixed with ambient air to generate reagent ions, which are then used for the ionization of gaseous organic compounds. A wide variety of substances, both polar and nonpolar, can be ionized.

The dc-GD-SFMS, recently commercially available from Thermo Fischer Scientific, has promoted the number of applications of this technique for the routine direct analysis of pure conducting and semi-conducting bulk samples, including Ti, Al and $\mathrm{Si}$. On the other hand, the new prototypes of pulsed-rf-GDTOFMS will extend the application of this technique not only for the analysis of conducting and non-conducting bulk materials but also for the analysis of thin coatings, which is of substantial interest in fields such as photovoltaic industry.

\section{Secondary ion mass spectrometry and sputtered neutral mass spectrometry}

Secondary ion mass spectrometry (SIMS) and sputtered neutral mass spectrometry (SNMS) represent the most powerful mass spectrometric techniques for surface and depth profile analysis, allowing the determination of element distributions on solid sample surfaces at trace and ultra trace element contents. ${ }^{125-127}$ SIMS is based on the use of energetic primary ions (between 0.25 and $30 \mathrm{keV}$ ) to bombard a sample surface. Upon entering the solid, the energy of the primary ions is transferred through binary collisions to the atoms of the target. The target atoms are then displaced from their original sites, colliding with other target atoms and, thus, producing a collision cascade until the transferred energy is insufficient to cause atom displacement. Collision cascades that reach the surface may cause the ejection of sample material from the very first atomic layers (sputtering process). Most of these sputtered particles are neutral (secondary 
neutrals) but some are charged (secondary ions), and the range of energies of such secondary ions is independent of the energy of the primary ions and usually in the order of $10 \mathrm{eV}$. The secondary ions of given polarity are then collected using adequate electrical potentials, separated in a mass analyzer according to their mass to charge ratio and, finally, detected. In the case of the SNMS, the secondary ions are suppressed by a repeller voltage, whereas the secondary neutrals are post-ionised (either in an argon plasma, by electron impact ionization, or using a laser) and then analysed in the mass spectrometer. ${ }^{128}$

General capabilitites. SIMS and SNMS allow depth profiling analysis with a depth resolution in the low nanometre range (see Fig. 6), and the analysis of element distributions on solid surfaces with a lateral resolution in the sub-micron range. ${ }^{129}$ Lateral resolution depends on the microbeam diameter and can be as low as $20 \mathrm{~nm}$ for liquid metal ion guns $\left(\right.$ e.g. $\left.\mathrm{Ga}^{+}\right) .{ }^{130}$ Moreover, nanoSIMS is an ultra high resolution chemical imaging facility combining the sensitivity of a dynamic SIMS with a lateral resolution of about $100 \mathrm{~nm}$. SIMS and laser post-ionization SNMS show excellent properties to determine local inclusions in solid samples as well as to evaluate the interdiffusion of elements in thin coated systems of high interest (e.g. in new materials, semiconductor industry and archaeological samples). ${ }^{131,132}$ These techniques have been recently used to image and quantify targeted compounds, intrinsic elements, and molecules with subcellular resolution in single cells of both cell cultures and tissues (see Fig. 7 and 8). ${ }^{133}$ In this case, a finely focused primary ion beam sweeps the sample in a raster pattern and, simultaneously, the secondary ion intensities are saved as a function of beam position. Furthermore, SIMS has been successfully applied for isotopic measurements in nuclear astrophysics applications. In particular, nanoSIMS technology has recently extended the isotopic studies to considerably smaller sample scales $(\ll 500$ $\mathrm{nm})$. In this case, the primary beam path is strongly modified to become co-axial with the secondary beam within the objective column. This configuration imposes the use of primary ions of opposite sign to those of the observed secondary ions. For instance, $\mathrm{Si}$ - and $\mathrm{Ca}-\mathrm{Ti}$-isotopic compositions of presolar silicon

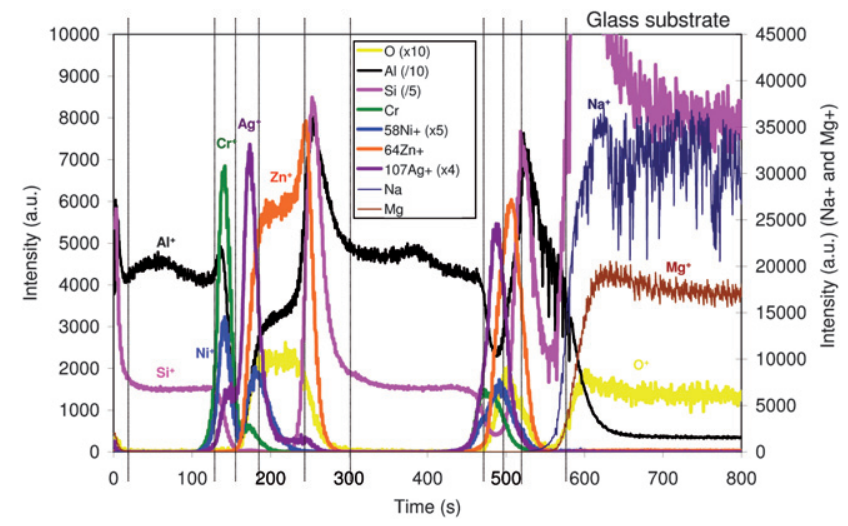

Fig. 6 Qualitative depth profile of thin coated glass (total thickness of the multi-layers about $200 \mathrm{~nm}$ ) obtained using the ToF-SIMS system. Operating conditions: Sputtering area $20 \times 20 \mu \mathrm{m}^{2}$ using $\mathrm{Ar}^{+}(40 \mathrm{nA}, 3$ $\mathrm{keV}$ ), concentric analysis area $5 \times 5 \mu \mathrm{m}^{2}$ using $\mathrm{Bi}^{+}(25 \mathrm{keV})$ (reprinted with permission from J. Anal. At. Spectrom., 2008, 23, 1239). carbide grains from supernovae have been determined using nanoSIMS. ${ }^{134}$

\section{Important aspects to be considered in SIMS and in SNMS}

Primary ions beam. The process of bombardment of the sample surface with energetic ions (sputtering process) alters the composition and structure of the sample. The altered layer will be probably enriched with implanted primary ions that will be sputtered along with the matrix material. However, ion implantation is not only considered as a drawback of SIMS and SNMS spectrometric methods, since it can be used to enhance ionisation efficiencies by orders of magnitude. The composition of an altered layer is homogenised due to redistribution of surface and sub-surface species by primary ions directly or within the collision cascades. Therefore, the variations of the measured intensities with the sputtering time do not necessarily reflect changes in sample composition and, additionally, the ultimate depth resolution is not the maximum depth from which secondary ions can be emitted (a few atomic layers), but is limited by the thickness of the altered layer $(1-10 \mathrm{~nm})$ comparable to the penetration depth of primary ions (related to the ion energies).

Primary ions commonly use are $\mathrm{Cs}^{+}, \mathrm{O}_{2}{ }^{+}, \mathrm{Ar}^{+}, \mathrm{Xe}^{+}$, and $\mathrm{Ga}^{+}$ as well as the more recently reported $\mathrm{Bi}$ and $\mathrm{Au}$ cluster ions $\left(\mathrm{Au}_{\mathrm{n}}{ }^{\mathrm{z}}, \mathrm{Bi}_{\mathrm{n}}{ }^{\mathrm{z}}\right)$, and even $\mathrm{C}_{60}{ }^{+}$. In comparison with noble gas primary ions $\left(\mathrm{Ar}^{+}\right.$and $\left.\mathrm{Xe}^{+}\right)$, the use of $\mathrm{O}_{2}{ }^{+}$and $\mathrm{Cs}^{+}$increases the ionisation probability for species that tend to form cations and anions, respectively. Moreover, $\mathrm{Ga}^{+}$can be employed to obtain extremely high lateral resolutions due to the finely delivered focussed beams, ${ }^{135}$ and the new trends that include the use of $\mathrm{C}_{60}{ }^{+}$and $\mathrm{Bi}$ and $\mathrm{Au}$ clusters for the analysis of polymers and biomolecules allow the improvement of yields in the production of high molecular weight fragments. Energy of the primary ions is close related to the achieved spatial resolution and, thus, higher energies result in better focussed beams (higher lateral resolution), and also in a higher sputtering rate that improves the sensitivity but degrades the depth resolution. Usually, the primary beam used for the sputtering process exhibits a Gaussian intensity profile and, therefore, convex craters are obtained. In this case, the secondary ions are collected from different depths degrading the depth resolution. In order to avoid this crater-shape effect, the primary beam is rastered/scanned over an area $\left(\right.$ e.g. $\left.400 \times 400 \mu \mathrm{m}^{2}\right)$, but the secondary ion intensities are only considered from the central, flat area of the crater $\left(\right.$ e.g. $\left.100 \times 100 \mu^{2}\right)$.

Experimental requirements. SIMS can be operated in two different modes, denoted as dynamic SIMS and static SIMS. In dynamic SIMS, the number of incident ions exceeds the number of surface atoms on the sample, leading mainly to elemental information with high count rates, thus permitting trace analysis. In contrast, static SIMS measurements are performed with a number of incident ions $\left(<10^{12}\right.$ ions $\left.\mathrm{cm}^{-2}\right)$ about one order of magnitude less than the number of atoms at the surface of the sample. In this case, the damage to the sample surface is minimized and ions are mainly emitted from the first atomic layers, promoting also desorption of large fragments. However, count rates are low and information is restricted to relatively abundant species within the very superficial layers of the target. In both cases, instrumental parameters need to be selected according to 


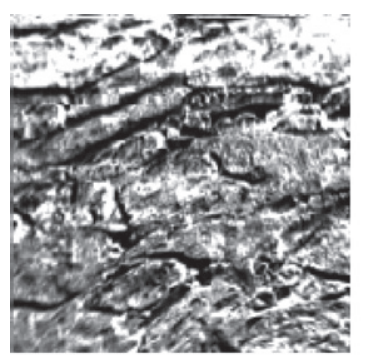

IIE

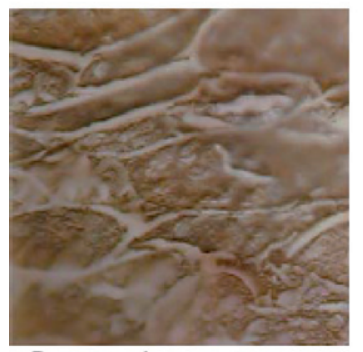

Opt. microscope

Area: $120 \times 120 \mu \mathrm{m}^{2}$

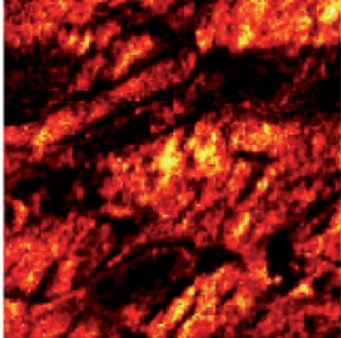

$\mathrm{Na}$

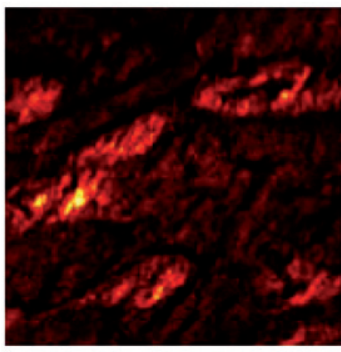

$\mathbf{K}$

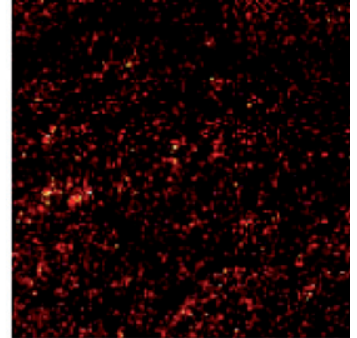

Mg

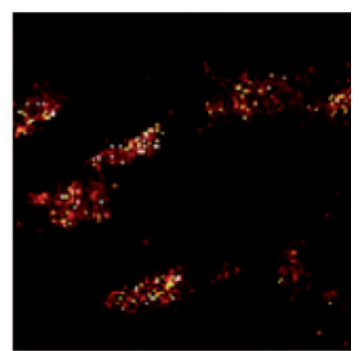

$\mathrm{K} / \mathrm{Na}$

Fig. 7 TOF-SIMS images, showing the elemental distribution of $\mathrm{Na}, \mathrm{Mg}, \mathrm{K}$, and $\mathrm{K} / \mathrm{Na}$ ratio, in a freeze-dried kidney tissue block. Additionally, ioninduced electron (IIE) and optical microscope images of the same sample area are displayed (reprinted with permission from Appl. Surf. Sci., 2006, 252, 6941).
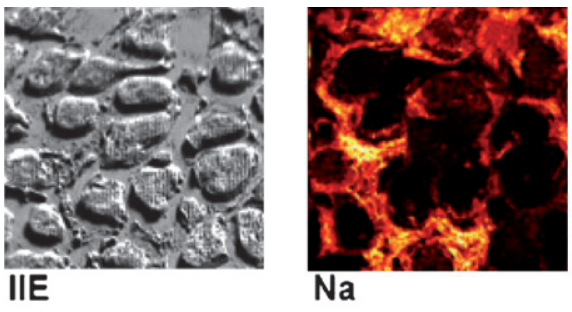

$\mathrm{Na}$

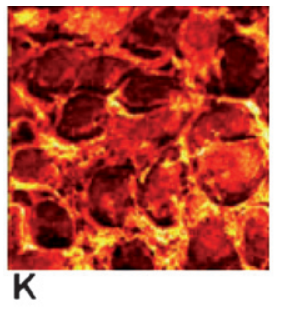

Area: $120 \times 120 \mu^{2}$

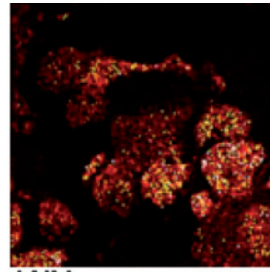

$\mathrm{K} / \mathrm{Na}$

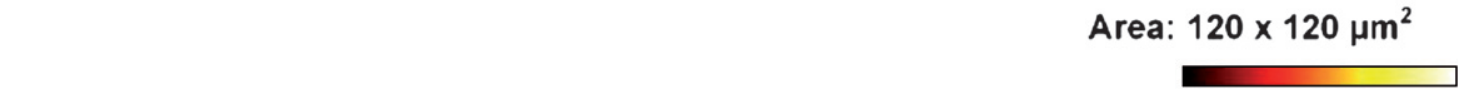

Fig. 8 Laser-SNMS images, showing the elemental distribution of Na, K, and K/Na ratio, in cell cultures (reprinted with permission from Appl. Surf. Sci., 2006, 252, 6941).

the most critical factors in the analysis (e.g. lateral resolution, depth resolution, or sensitivity), and the optimal conditions represent a compromise between those different factors.

All components of SIMS and SNMS systems are housed in an ultra-high vacuum chamber and, thus, any substance that contaminates the chamber of the instrument under the vacuum conditions can not be analyzed within a reasonably short period of time. Whereas the sample preparation usually takes a few minutes in LA-ICP-MS and GD-MS analyses, in SIMS this time could be as long as one night if the sample contains, for instance a lot of water adsorbed. Furthermore, as a consequence of the vacuum requirements in SIMS/SNMS, the sample throughput is small compared to other direct solid analysis techniques such as LA-ICP-MS or GD-MS. Nevertheless, thin depth profile analysis of a non-outgassing sample using dynamic SIMS with quadrupole or magnetic sector analysers at optimised conditions could be performed in tens of minutes. Both the samples and the sample holders should be handled with clean tweezers and polyethylene gloves in order to avoid contamination of the surface. For instance, typical silicone has a very low surface tension and, thus, preferentially segregates on the sample surface. Silicone is easily introduced by various materials such as oils, greases, sealants, adhesives, surfactant, and medical devices and, therefore, in the case of surface contamination, a strong signal from silicone will be detected rather than a signal from the sample. ${ }^{136}$ On the other hand, an additional requirement for the analysis of poorly conducting samples is the use of an electron gun to compensate the charge that builds up during ion bombardment.

Coupling the ion probe to different mass analysers. Enhancing of mass resolving power to improve precision and accuracy of the analyses has been achieved by using various mass analyzers (double focusing magnetic sector, quadrupole mass analyzer). 
However, only one specific ion image can be acquired at a time using these "sequential" mass analyzers. This major restriction has been very limiting in terms of in-depth resolution, and sequential images of various species cannot be properly correlated. To overcome this difficulty time-of-flight (TOF) spectrometer, which can record simultaneously all the secondary ions formed over a wide mass range, has been used. Moreover, TOF analyzers can correct for small differences in initial energy and angle in order to achieve high mass resolution $(>10000)$. However, TOF analysis required a pulsed primary ion beam usually delivering less energy than continuous sources, thus strongly decreasing the secondary elemental ion yield but allowing a better collection of molecular ions. Therefore, TOFSIMS instruments show important advantages in the analysis of molecular compounds in comparison to quadrupole and magnetic sector field mass analyzers, such as their higher ion transmission, the parallel detection of all masses, and the unlimited mass range. ${ }^{137}$

It needs to be highlighted that combining the spectral, imaging, and depth information obtained by SIMS, it is possible to visualize three dimensional sample structures. ${ }^{138,139}$ For instance, TOF-SIMS allows parallel mass detection with high depth resolution and high image resolution. ${ }^{140,141}$ However, it should be stated that high sensitivity is also required for ultrahigh lateral resolution $(<150 \mathrm{~nm})$ because focusing of the primary beam to smaller diameters also reduces the beam intensity. Therefore, in nanoSIMS, the ion probe has been coupled to a double focusing mass spectrometer, with an electrostatic filter and a magnetic sector in the Mattauch-Herzog configuration. ${ }^{\mathbf{1 4 2}}$

Quantification procedure. Quantification of SIMS and SNMS results is a difficult process since the secondary ion intensity depends on several parameters, including the type of primary ions, their energy, and their angle of incidence with respect to the surface normal. The element of interest, the matrix in which it is located, the background pressure in the analysis environment, as well as the crystal orientation are also important parameters that it is necessary to take into account. Moreover, it should be stated that the ionization probabilities can vary by orders of magnitude depending on the mentioned parameters. The relative influence of these parameters varies between different matrices and, therefore, quantification methods to convert the qualitative profiles (temporal variation of secondary ion intensities) into quantitative profiles (concentration depth profiles) are generally tedious and time consuming. For instance, the existence of "matrix effects" in secondary ion mass spectrometric analysis in different biological sample preparations has been described. ${ }^{143}$ Even if the matrix chemical composition of $\mathrm{C}, \mathrm{H}, \mathrm{O}$, and $\mathrm{N}$ is similar for all tissues and the surrounding resin, a matrix effect has been observed. Tables 2 and 3 highlight the dependence of sensitivity $\left(\mathrm{RSF}^{-1}\right)$ on the element of interest, the sign of the ions charge (cation or anion, respectively), and the type of primary ions. ${ }^{144}$ Low RSFs mean high sensitivity and, as a consequence, quantification procedure of an unknown sample is generally carried out using a calibration sample with a close matrix stoichiometric, which contains a known amount of the relevant element (matrix-matched calibration).

Trends. The use of polyatomic primary beams (e.g. Au and Bi clusters) allows a significantly increased yield of molecularcorrelated fragments, enabling higher signal intensities and better secondary ion efficiencies. ${ }^{145}$ The lateral resolution is currently in the order of $2-4 \mu \mathrm{m}$ for $\mathrm{Bi}_{\mathrm{n}}{ }^{+} / \mathrm{Au}_{3}{ }^{+}$and $\mathrm{C}_{60}{ }^{+}$, respectively. Although numerous applications have been

Table 2 The following relative sensitivity factors (RSFs) have been measured for oxygen primary ion bombardment, positive secondary ions, and a silicon matrix. (Reprinted with permission from Int. J. Mass Spectrometry. Ion Proc., 1995, 143, 43)

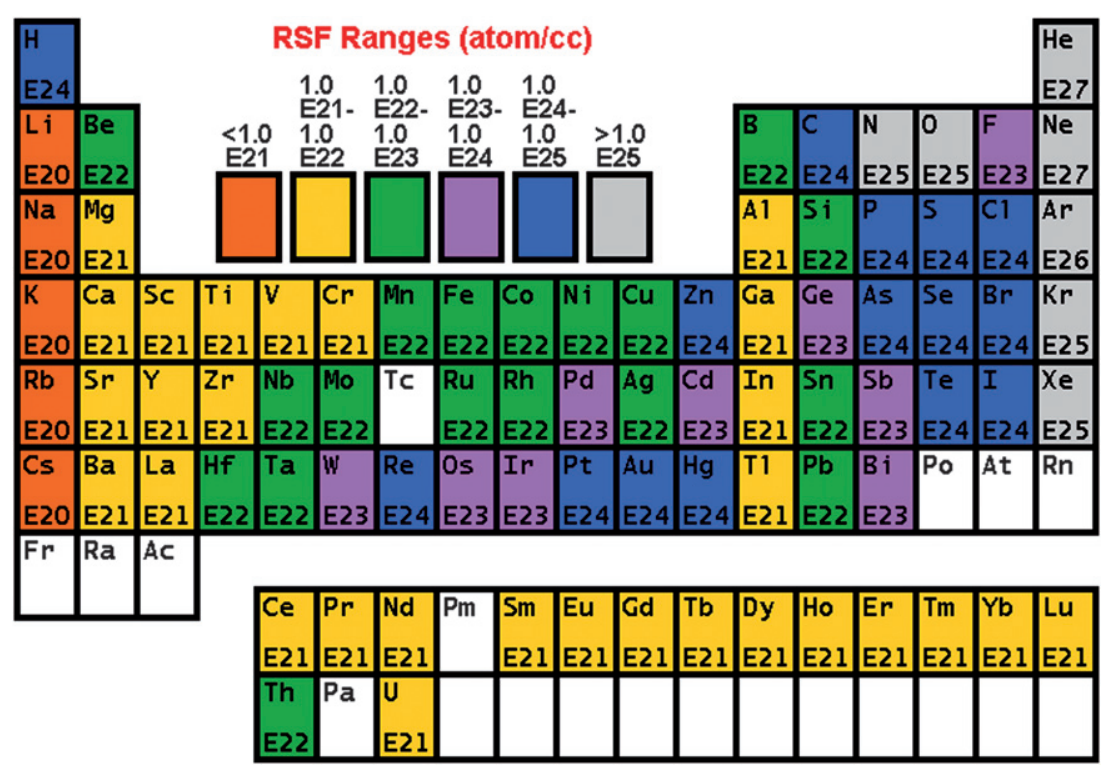


Table 3 The following relative sensitivity factors (RSFs) have been measured for caesium primary ion bombardment, negative secondary ions, and a silicon matrix. (Reprinted with permission from Int. J. Mass Spectrometry. Ion Proc., 1995, 143, 43)

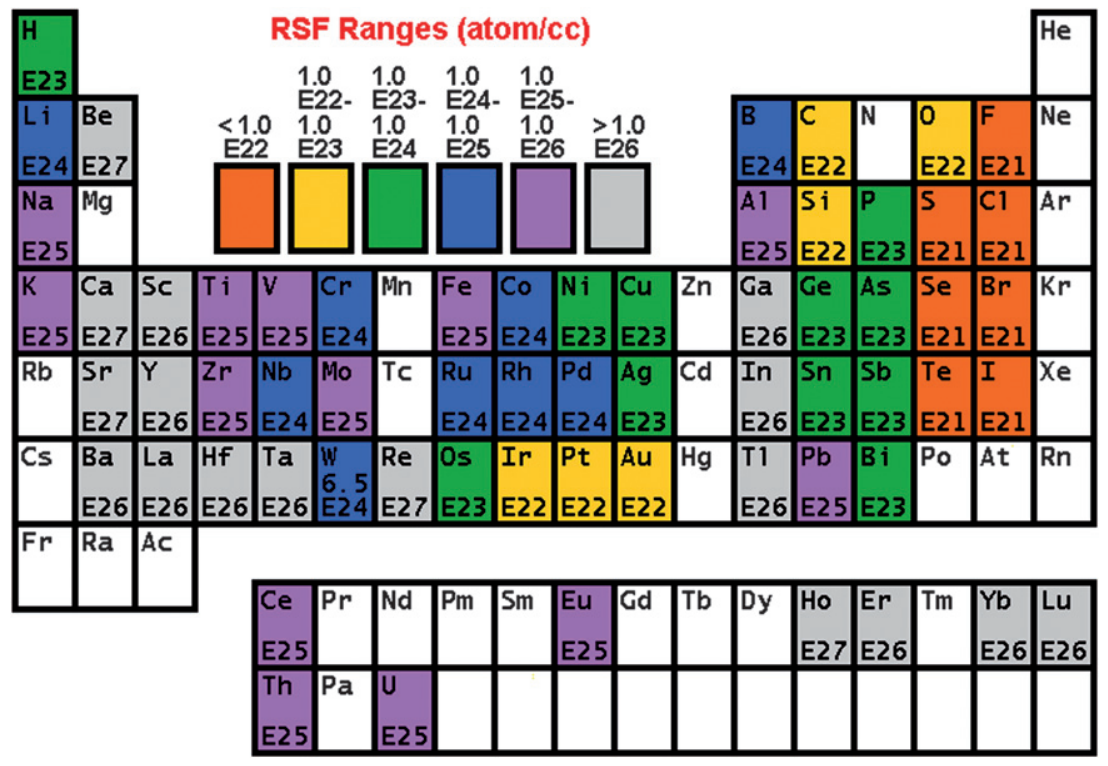

recently reported for imaging on biotissues using SIMS and SNMS, it should be stressed that the difficulties observed to desorb big proteins (mainly lipids) as well as the low sensitivity achieved are two of the main limitations of these mass spectrometric methods. Nevertheless, the recent development of a new system for imaging MS using $\mathrm{MeV}$ ion beams $(\mathrm{MeV}$ SIMS) has demonstrated more than 1000 -fold increase in molecular ion yield from a peptide sample (1154 Da), compared to $\mathrm{keV}$ ion irradiation. ${ }^{146}$ This significant enhancement of the molecular ion yield is attributed to electronic excitation induced in the near-surface region by the impact of high energy ions. These results indicate that the MeV-SIMS technique can be a powerful tool for high-resolution imaging in the mass range from 100 to over $1000 \mathrm{Da}$. Moreover, the identification of different molecules in complex samples, such as biological matrices, has been improved through the development of different statistical methods for the analysis of mass spectra and images. ${ }^{147}$ Additionally, the use of femtosecond lasers for the ionisation step in laser SNMS has shown to radically reduce the fragmentation of large molecules, which otherwise is a limiting factor for the biomolecule-identification capability of this technique. ${ }^{148}$ On the other hand, the latest high-resolution dynamic SIMS equipment (e.g. CAMECA NanoSIMS 50) has a high lateral resolution ( $\leq 50 \mathrm{~nm}$ using cesium ions, $\leq 150 \mathrm{~nm}$ using oxygen ions), the ability to detect simultaneously 5 different ions from the same micro-volume and a very good transmission even at high mass resolution $(60 \%$ at $\mathrm{m} / \Delta \mathrm{m}=$ 5000). Therefore, the decisive capability of this new instrument has allowed recent methodological advances in the field of biological imaging. ${ }^{149}$

Table 4 Selected fields and types of applications of the studied mass spectrometric methods

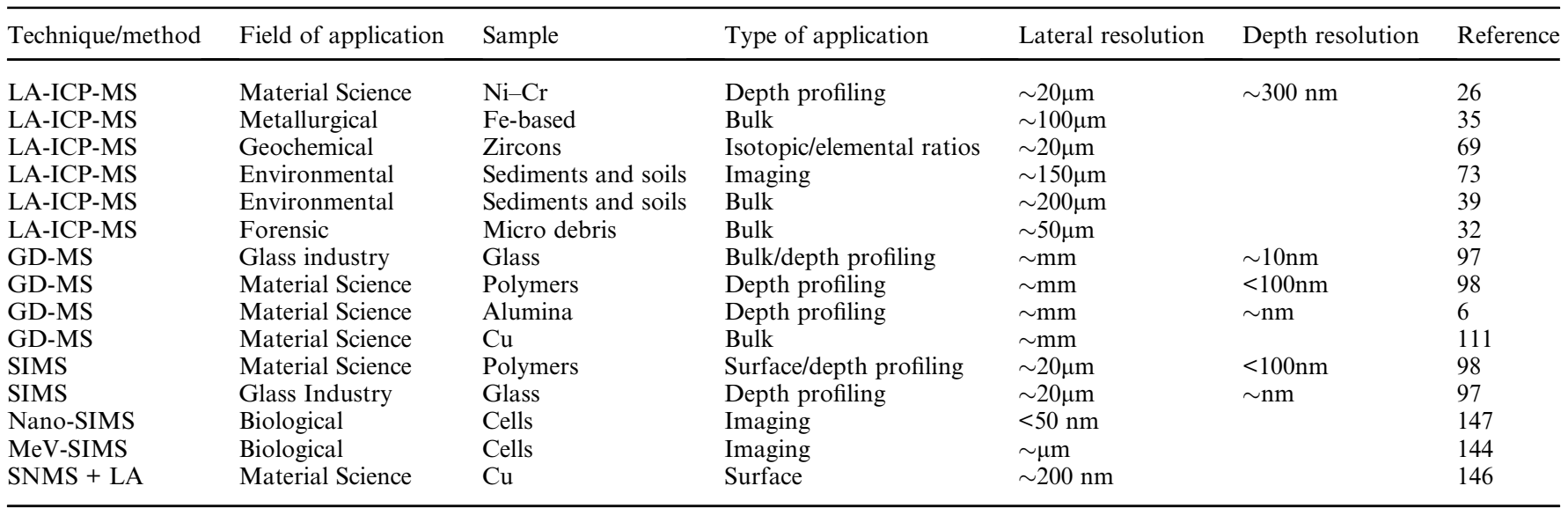


Table 5 Summary of the most relevant characteristics of the studied mass spectrometric methods

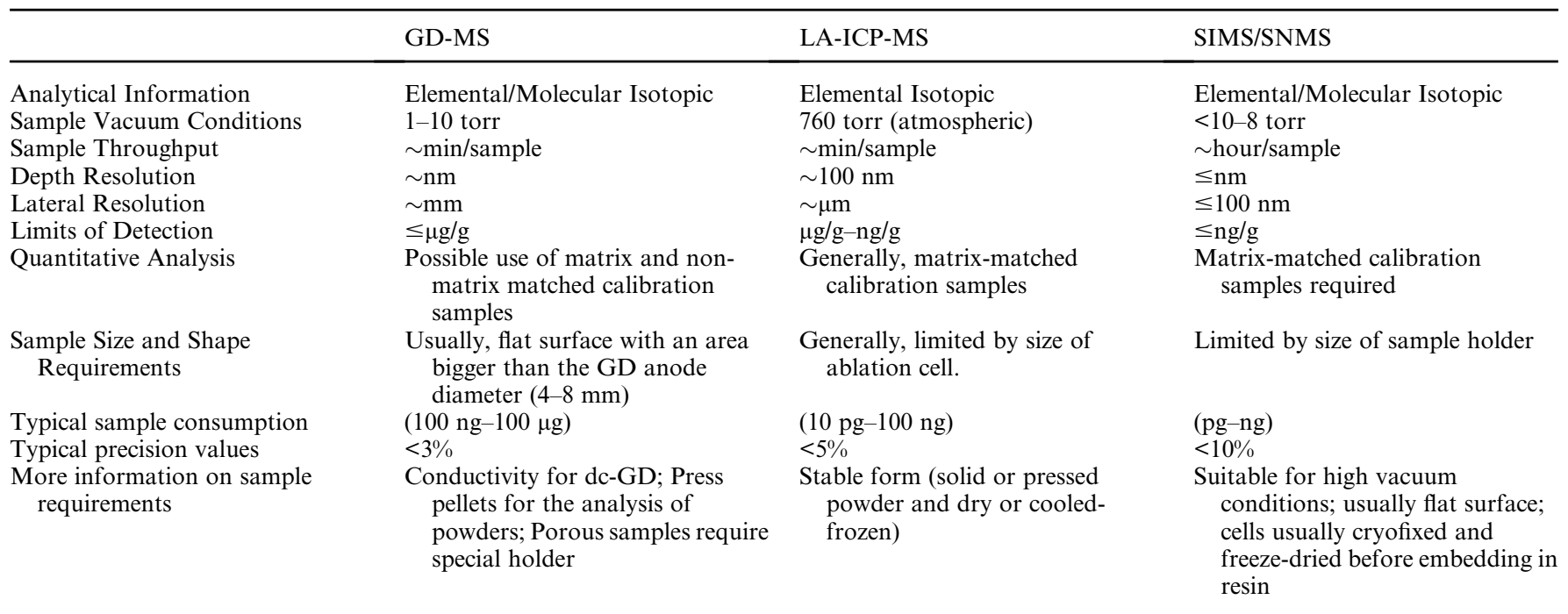

\section{Conclusions}

Despite the numerous advantages reported for the reviewed mass spectrometric methods, there are some specific topics that still need further investigation in order to better understand all the processes involved in the analysis and, therefore, to extend their fields of application. Further development and improvement of LA-ICP-MS, GD-MS, and SIMS/SNMS instrumentation requires the fundamental understanding of key-phenomena, such as, the understanding of the sputtering/ablation mechanisms and ionization/vaporization processes, the characterization of sputtered/ablated surfaces, ion/particles transport phenomena, and detection methods.

Nevertheless, even recognizing the limitations of these mass spectrometric methods, GD-MS, LA-ICP-MS and SIMS/ SNMS have already demonstrated their powerful analytical capabilities (e.g. high spatial resolution, high sensitivity, low limits of detection, multi-element capabilities, etc.) through a great variety of applications, including the analysis of different types of matrices such as environmental wastes, biological samples, geochemical materials, coatings, and semiconductors. In particular, Table 4 highlights some selected fields and types of applications of the studied mass spectrometric methods. It is observed that LA-ICP-MS is used for a wide variety of applications, providing a high lateral resolution (tens of $\mu \mathrm{m}$ ) and an adequate depth resolution (hundreds of $\mathrm{nm}$ ). GD-MS is mainly used for material science applications in bulk and depth profile analysis, showing a poor lateral resolution $(\sim \mathrm{mm})$ but an excellent depth resolution $(\sim \mathrm{nm})$. Furthermore, SIMS provides excellent lateral resolution (nm$\mu \mathrm{m})$ and excellent depth resolution $(\sim \mathrm{nm})$, being adequate for imaging and depth profiling applications in biology and material science.

It could be concluded that the own advantages and drawbacks of these mass spectrometric techniques, summarized in Table 5, convert them into a set of complementary analytical tools, which cover many fields of applications in the area of direct solid analysis.

\section{Acknowledgements}

B. Fernandez and J. Pisonero gratefully acknowledge financial support from "Juan de la Cierva" and "Ramon y Cajal" Research Programs of the Ministry of Science and Innovation of Spain, respectively. Both Programs are co-financed by the European Social Fund. J. Pisonero acknowledges support from the EMDPA Project (FP6 Contract STREP-NMP, N 032202) of the European Union.

\section{References}

1 Laser-Ablation-ICPMS in the Earth Sciences, ed. P. Sylvester, Mineralogical Association of Canada, St. John's, Newfoundland, 2001, ISBN 0-921294-29-8.

2 W. W. Harrison, J. Anal. At. Spectrom., 1988, 3, 867-872.

3 J. C. Vickerman, A. Brown and N. M. Reed, Secondary Ion Mass Spectrometry: Principles and Applications, Claredon Press, Oxford, 1989.

4 J. Pisonero and D. Günther, Mass Spectrom. Rev., 2008, 27, 609623.

5 J. S. Becker and H. J. Dietze, Int. J. Mass Spectrom. Ion Processes, $2000,197,1-35$.

6 M. Hohl, A. Kanzari, J. Michler, Th. Nelis, K. Fuhrer and M. Gonin, Surf. Interface Anal., 2006, 38, 292-295.

7 A. N. Halliday, D.-C. Lee, J. N. Christensen, A. J. Walder, P. A. Freedman, C. E. Jones, C. M. Hall, W. Yi and D. Teagle, Geochim. Cosmochim. Acta, 1995, 146(147), 21-33.

8 N. T. Kita, S. Mostefaoui, Y. Z. Liu, S. Togashi and Y. Morishita, Appl. Surf. Sci., 2003, 203-204, 806-809.

9 M. Hamester, L. Rottmann and J. Hinrichs, LaborPraxis, 2006, (Jan./Feb.), 42.

10 F. Vanhaecke, Anal. Bioanal. Chem., 2002, 372, 20-21.

11 M. Resano, E. García-Ruiz, K. S. McIntosh, J. Hinrichs, I. Deconinck and F. Vanhaecke, J. Anal. At. Spectrom., 2006, 21, 899-909.

12 S. D. Tanner, V. I. Baranov and D. R. Bandura, Spectrochim. Acta Part B, 2002, 57, 1361-1452.

13 C. Latkoczy and D. Günther, J. Anal. Atom. Spectrom., 2002, 17, 1264-1270.

14 H. Cousin and B. Magyar, Mikrochim. Acta, 1994, 113, 313-323.

15 M. Odegård and M. Hamester, Geost. Geoanal. Res., 1997, 21, 245-251.

16 K. Wittmaack, Surf. Interface Anal., 1998, 26, 290-305. 
17 H. Scholze, E. Hoffmann, C. Lüdke and A. Platalla, Fresenius J. Anal. Chem., 1996, 355, 892-894.

18 D. Günther, H. Cousin, B. Magyar and I. Leopold, J. Anal. At. Spectrom., 1997, 12, 165-170.

19 M. Wälle, J. Koch and D. Günther, J. Anal. At. Spectrom., 2008, 9, 1285-1289.

20 A. L. Gray, Analyst, 1985, 110, 551-556.

21 B. Hattendorf, C. Latkoczy and D. Günther, Anal. Chem., 2003, 75, 341A-347A.

22 S. M. Eggins, L. P. J. Kinsley and J. M. G. Shelley, Appl. Surf. Sci., 1998, 127-129, 278-286.

23 J. Koch, S. Schlamp, T. Rosgen, D. Fliegel and D. Günther, Spectrochim. Acta Part B, 2007, 62, 20-29.

24 J. Koch, M. Wälle, S. Schlamp, T. Rösgen and D. Günther, Spectrochim. Acta Part B, 2008, 63, 37-41.

25 M. P. Mateo, C. C. García and R. Hergenröder, Anal. Chem., 2007, 79, 4908-4914.

26 J. Pisonero, J. Koch, M. Wälle, W. Hartung, N. D. Spencer and D. Günther, Anal. Chem., 2007, 79, 2325-2333.

27 Q. Bian, C. C. Garcia, J. Koch and K. Niemax, J. Anal. Atom. Spectrom., 2006, 21, 187-191.

28 J. Koch, M. Wälle, J. Pisonero and D. Günther, J. Anal. At. Spectrom., 2006, 21, 932-940.

29 I. Horn and F. von Blanckenburg, Spectrochim. Acta, Part B, 2007, 62, 410-422.

30 G. Ballihaut, F. Claverie, C. Pécheyran, S. Mounicou, R. Grimaud and R. Lobinski, Anal. Chem., 2007, 79, 6874-6880.

31 J. Feldmann, A. Kindness and P. Ek, J. Anal. At. Spectrom., 2002, 17, 813-818.

32 C. J. Scadding, R. J. Watling and A. G. Thomas, Talanta, 2005, 67, 414-424.

$33 \mathrm{http}: / /$ www.nitecrime.eu.com/.

34 C. Latkoczy, S. Becker, M. Ducking, D. Gunther, J. A. Hoogewerff, J. R. Almirall, J. Buscaglia, A. Dobney, R. D. Koons, S. Montero, G. J. O. van der Peijl, W. R. S. Stoecklein, T. Trejos, J. R. Watling and V. S. Zdanowicz, J. Forensic Scie., 2005, 50(6), $1327-1341$.

35 V. Mozna, J. Pisonero, M. Hola, V. Kanicky and D. Günther, J. Anal. At. Spectrom., 2006, 21, 1194-1201.

36 H. P. Longerich, D. Günther and S. E. Jackson, Fresenius J. Anal. Chem., 1996, 355, 538-542.

37 A. M. Leach and G. M. Hieftje, J. Anal. At. Spectrom., 2002, 17, $852-857$.

38 M. Guillong, K. Hametner, E. Reusser, S. A. Wilson and D. Günther, Geost. Geoanal. Res, 2005, 29, 315-331.

39 L. Arroyo, T. Trejos, P. R. Gardinali and J. R. Almirall, Spectrochim. Acta Part B, 2009, 64, 16-25.

40 K. P. Jochum, B. Stoll, K. Herwing, M. Amino, W. Abouchami and A. W. Hofmann, Int. J. Mass Spectrom., 2005, 242, 281-289.

41 H. L. Yuan, S. Gao, Y. Luo, C. L. Zong, M. L. Dai, X. M. Liu and C. R. Diwu, Acta Petrologica Sinica, 2007, 23, 233-239.

42 L. Kempenaers, K. Janssens, K. P. Jochum, L. Vincze, B. Vekemans, A. Somogyi, M. Drakopoulos and F. Adams, J. Anal. At. Spectrom., 2003, 18, 350-357.

43 E. P. Vicenzi, S. Eggins, A. Logan and R. Wysoczanski, J. Res. Ntl. Inst. Stnd. Techno., 2002, 107, 719-727.

44 B. J. Fryer, S. E. Jackson and H. P. Longerich, Can. Mineral., 1995, 33, 303-312.

45 J. Gonzalez, X. L. Mao, J. Roy, S. S. Mao and R. E. Russo, J. Anal. At. Spectrom., 2002, 17, 1108-1113.

46 C. C. García, H. Lindner and K. Niemax, J. Anal. At. Spectrom., 2009, 24, 14-26.

47 D. Figg and M. Kahr, Appl. Spectrosc., 1997, 51, 1185-1192.

48 H. R. Kuhn and D. Günther, Anal. Chem., 2003, 75, 747-753.

49 S. E. Jackson and D. Günther, J. Anal. At. Spectrom., 2003, 18, 205-212.

50 B. Fernández, F. Claverie, C. Pécheyran and O. F. X. Donard, Trends Anal. Chem., 2007, 26, 951-966.

51 F. Poitrasson, X. Mao, S. S. Mao, R. Freydier and R. E. Russo, Anal. Chem., 2005, 75, 6184-6190.

52 J. Gonzalez, S. H. Dundas, C. Y. Liu, X. Mao and R. E. Russo, J. Anal. At. Spectrom., 2004, 19, 267-272.

53 C. Liu, X. L. Mao, S. S. Mao, X. Zeng, R. Greif and R. E. Russo, Anal. Chem., 2004, 76, 379-383.

54 J. Koch, A. von Bohlen, R. Hergenröder and K. Niemax, J. Anal. At. Spectrom., 2004, 19, 267-272.
55 M. Guillong and D. Günther, J. Anal. At. Spectrom., 2002, 17, 831837.

56 P. Arrowsmith and K. Steven, Appl. Spectrosc., 1988, 42, 1231-1239.

57 D. B. Aeschliman, S. J. Bajic, D. P. Baldwin and R. S. Houk, J. Anal. At. Spectrom., 2003, 18, 1008-1014.

58 R. Hergenröder, J. Anal. At. Spectrom., 2006, 21, 505-516.

59 R. Hergenröder, Spectrochim. Acta Part B, 2006, 61, 284-300.

60 H. R. Kuhn, J. Koch, R. Hergenröder, K. Niemax, M. Kalberer and D. Günther, J. Anal. At. Spectrom., 2005, 20, 894-900.

61 H. R. Kuhn, M. Guillong and D. Günther, Anal. Bioanal. Chem., 2004, 378, 1069-1074.

62 B. N. Chichkov, C. Momma, S. Nolte, F. von Alvensleben and A. Tünnermann, Appl. Phys. A, 1996, 63, 109-115.

63 R. Hergenröder, O. Samek and V. Hommes, Mass Spectrom. Rev., 2006, 25, 551-572.

64 I. Horn and F. Von Blanckenburg, Spectrochim. Acta Part B, 2007, 62, 410-422.

65 R. E. Russo, X. Mao, J. J. Gonzalez and S. S. Mao, J. Anal. At. Spectrom., 2002, 17, 1072-1075.

66 J. Koch, H. Lindner, A. von Bohlen, R. Hergenröder and K. Niemax, J. Anal. At. Spectrom., 2005, 20, 901-906.

67 I. Kroslakova and D. Günther, J. Anal. At. Spectrom., 2007, 22, 51-62.

68 Q. Z. Bian, J. Koch, H. Lindner, H. Berndt, R. Hergenröder and K. Niemax, J. Anal. At. Spectrom., 2005, 20, 736-740.

69 T. Iizuka and T. Hirata, Geochem. J, 2004, 38, 229-241.

70 J. P. Bernal, S. M. Eggins and M. T. Mcculloch, J. Anal. At. Spectrom., 2005, 20, 1240-1249.

71 H. Sela, Z. Karpas, M. Zoriy, C. Pickhardt and J. S. Becker, Int. J. Mass Spectrom., 2007, 261, 199-207.

72 S. F. Boulyga, J. Heilmann, T. Prohaska and K. G. Heumann, Anal. Bioanal. Chem., 2007, 389, 697-706.

73 B. Fernández, F. Claverie, C. Pécheyran and O. F. X. Donard, J. Anal. At. Spectrom., 2008, 23, 367-377.

74 B. Fernández, F. Claverie, C. Pécheyran, J. Alexis and O. F. X. Donard, Anal. Chem., 2008, 80, 6981-6994.

75 D. Bleiner, F. Belloni, D. Doria, A. Lorusso and V. Nassisi, J. Anal. At. Spectrom., 2005, 20, 1337-1343.

76 J. Pisonero, D. Fliegel and D. Günther, J. Anal. At. Spectrom., 2006, 21, 922-931.

77 A. J. G. Manka and P. R. D. Mason, J. Anal. At. Spectrom., 1999, 14, 1143-1153.

78 O. Samek, V. Margetic, N. Von Wiren, A. Michels, K. Niemax and R. Hergenröder, Appl. Phys. A, 2004, 79, 957-960.

79 Y. Liu and M. Niemz, Laser Med. Sci., 2007, 22, 171-174.

80 J. Koch and D. Günther, Anal. Bioanal. Chem., 2007, 387, 149-153.

81 C. O'Connor, B. L. Sharp and P. Evans, J. Anal. At. Spectrom., 2006, 21, 556.

82 D. Autrique, A. Bogaerts, H. Lindner, C. C. Garcia and K. Niemax, Spectrochim. Acta Part B, 2008, 63(2), 257-270.

83 D. Bleiner, A. Bogaerts, F. Belloni and V. Nassisi Vincenzo, J. Appl. Phys., 2007, 101(8), 1-5.

84 B. Annemie, C. Zhaoyang and B. Davide, J. Anal. At. Spectrom., 2006, 21, 384-395.

85 V. Hoffmann, M. Kasik, P. K. Robinson and C. Venzago, Anal. Bioanal. Chem., 2005, 381, 173-188.

86 A. Bogaerts, J. Anal. At. Spectrom., 2007, 22, 13-40.

87 A. Bogaerts, K. A. Temelkov, N. K. Vuchkov and R. Gijbels, Spectrochim. Acta Part B, 2007, 62, 325-336.

88 Glow Discharge Plasmas in Analytical Spectroscopy, Marcus R K, Broekaert J A C (eds), John Wiley \& Sons Ltd., England, 2003.

89 J. Pisonero, J. M. Costa, R. Pereiro, N. Bordel and A. Sanz-Medel, Anal. Bioanal. Chem., 2004, 379, 658-667.

90 J. Pisonero, B. Fernández, R. Pereiro, N. Bordel and A. Sanz-Medel, Trends Anal. Chem., 2006, 25, 11-18.

91 R. Escobar, E. Forniés and J. M. Albella, J. Anal. At. Spectrom., 2005, 20, 1116-1120.

92 F. L. King and C. Pan, Anal. Chem., 1993, 65, 3187-3193.

93 H. Grimm, Spectrochim Acta Part B, 1968, 23, 443-454.

94 R. E. Steiner, C. L. Lewis and F. King, Anal. Chem., 1997, 69, 17151721.

95 F. L. King and C. Pan, Anal. Chem., 1993, 65, 3187-3193.

96 C. L. Lewis, M. A. Moser, D. E. Dale, W. Hang, C. Hassell, F. L. King and V. Majidi, Anal. Chem., 2003, 75, 1983-1996.

97 J. Pisonero, K. Turney, N. Bordel, A. Sanz-Medel and W. W. Harrison, J. Anal. At. Spectrom., 2003, 18, 624-628. 
98 S. Itoh, H. Yamaguchi, T. Yoshioka, T. Kimura and T. Kobayashi, Mater T JIM, 2000, 41, 516-521.

99 A. C. Muñiz, J. Pisonero, L. Lobo, C. Gonzalez, N. Bordel, R. Pereiro, A. Tempez, P. Chapon, N. Tuccitto, A. Licciardello and A. Sanz-Medel, J. Anal. At. Spectrom., 2008, 23, 1239-1246.

100 N. Tuccitto, L. Lobo, A. Tempez, I. Delfanti, P. Chapon, S. Canulescu, N. Bordel, J. Michler and A. Licciardello, Rapid Communication in Mass Spectrom., 2009, 23(5), 549-556.

101 A. Bogaerts, W. Verscharen and E. Steers, Spectrochim. Acta Part B, 2004, 59, 1403-1411.

102 A. Bogaerts, Z. Chen and R. Gijbels, Surf. Inter. Anal., 2003, 35, 593-603.

103 H. J. Kim, E. H. Piepmeier, G. L. Beck, G. G. Brumbaugh and O. T. Farmer, Anal. Chem., 1990, 62, 1368-1373.

104 G. Absalan, C. L. Chakrabarti, K. L. Headrick, M. Parker and R. K. Marcus, Anal. Chem., 1998, 70, 3434-3443.

105 P. H. Ratliff and W. W. Harrison, Appl. Spectrosc., 1995, 49, 863871.

106 A. Bogaerts, J. Anal. Atom. Spectrom., 2008, 23, 1476-1486.

107 A. Menéndez, J. Pisonero, R. Pereiro, N. Bordel and A. Sanz-Medel, J. Anal. Atom. Spectrom., 2003, 18, 557-563.

108 R. S. Mason, P. D. Millar and I. P. Mortiner, Physical Review E, 1997, 55, 7462-7473.

109 E. P. Hastings and W. W. Harrison, J. Anal. At. Spectrom., 2004, 19, $1268-1274$.

110 M. Vazquez, J. M. Costa, R. Pereiro, N. Bordel and A. Sanz-Medel, J. Anal. At. Spectrom., 2003, 18, 864-871.

111 R. Matschat, J. Hinrichs and H. Kipphardt, Anal. Bioanal. Chem., 2006, 386, 125-141.

112 W. Vieth and J. C. Huneke, Spectrochim. Acta, Part B, 1991, 46, 137-153.

113 M. Kasik, C. Venzago and R. Dorka, J. Anal. At. Spectrom., 2003, 18, 603-611.

114 Y. Xing, L. Xiaojia and W. Haizhou, International J. Mass Spectrom., 2007, 262, 25-32.

115 P. Håkansson, Braz. J. Phys., 1999, 29(3), 422-427.

116 S. Gendt, R. E. Van Greiken, S. K. Ohorodnik and W. W. Harrison, Anal. Chem., 1996, 67, 1026-1033.

117 M. Vazquez, J. Pisonero, J. M. Costa, R. Pereiro, N. Bordel and A. Sanz-Medel, J. Anal. At. Spectrom., 2003, 18, 612-617.

118 J. Pisonero, Anal. Bioanal. Chem., 2006, 384, 47-49.

119 N. Jakubowski, R. Dorka, E. Steers and A. Tempez, J. Anal. At. Spectrom., 2007, 22, 722-735.

120 K. Newman, R. S. Mason, D. R. Williams and I. P. Mortimer, J. Anal. At. Spectrom., 2004, 19, 1192-1198.

121 W. W. Harrison, J. Anal. At. Spectrom., 1998, 13, 1051-1056.

122 C. R. Lewis, G. P. Jackson, S. K. Doorn, V. Majidi and F. L. King, Spectrochim. Acta Part B, 2001, 56, 487-501.

123 F. J. Andrade, J. T. Shelley, W. C. Wetzel, M. R. Webb, G. Gamez, S. J. Ray and G. M. Hieftje, Anal. Chem., 2008, 80, 2646-2653.

124 F. J. Andrade, J. T. Shelley, W. C. Wetzel, M. R. Webb, G. Gamez, S. J. Ray and G. M. Hieftje, Anal. Chem., 2008, 80, 2654-2663.
125 J. C. Vickerman, Surface Analysis-The Principal Techniques, Wiley, Chichester, 1998, pp.135-214.

126 E. Deloule, Geost. Geoanal. Res, 2007, 30(3), 175-182.

127 M. J. Whitehouse, Geostand. Geoanal. Res., 2004, 28, 195-201.

128 A. Benninghoven, F. G. Rüdenauer and H. W. Werner, Secondary Ion Mass Spectrometry: Basic Concepts, Instrumental Aspects, Applications and Trends, Wiley, New York, 1987.

129 R. Castaing and G. Slodzian, J. Microsc., 1962, 1, 395-410.

130 R. Levi-Setti, G. Crow and Y. L. Wang, Scanning Electron Microsc., 1985, 2, 535-552.

131 R. Orinakova, A. Orinak, H. F. Arlinghaus, S. Hellweg, M. Kupkova and M. Streckova, Surf. Interface Anal., 2006, 38, 833-837.

132 M. P. McCann, W. F. Calaway, M. J. Pellin, I. V. Veryovkin, I. Constantinides, A. Adriaens and F. Adams, Surf. Interface Anal., 2002, 33, 394-400.

133 H. F. Arlinghaus, C. Kriegeskotte, M. Fartmann, A. Wittig, W. Sauerwein and D. Lipinsky, Appl. Surf. Sci., 2006, 252, 69416948.

134 A. Besmehn and P. Hoppe, Geochim. Cosmochim. Acta, 2003, 67(24), 4693-4703.

135 H. Nygren, P. Malmberg, C. Kriegeskotte and H. F. Arlinghaus, Febs. Letters, 2004, 566, 291-293.

136 TRIFT-II (triple focusing time-of-flight) ToF-SIMS operator's guide, Physical Electronics, Chanhassen, MN, USA.

137 B. T. Chait and K. G. Standing, Int. J. Mass Spectrom. Ion Phys., 1981, 40, 185-193.

138 A. Wucher, J. Cheng, L. Zheng, D. Willingham and N. Winograd, Appl. Surf. Sci., 2008, DOI: 10.1016/j.apsusc.2008.05.246, in Press.

139 A. Wucher, J. Cheng and N. Winograd, Anal. Chem., 2007, 79, 55295539 .

140 O. Anderson, V. Sheumann, U. Rothlaar and V. Rupertus, Glass Sci. Technol., 2004, 77, 159-165.

141 E. A. Jones, N. P. Lockyer and J. C. Vickerman, Anal. Chem., 2008, 80, 2125-2132.

142 G. Slodzian, B. Daigne, F. Girard, F. Boust and F. Hillion, Biol. Cell, 1992, 74, 43-50.

143 M. S. Burns, D. M. File, V. Deline and P. Galle, Scanning Electron Microsc., 1986, 4, 1277-1290.

144 R. G. Wilson, Int. J. Mass Spectrometry. Ion Proc., 1995, 143, $43-49$.

145 S. Hellweg, A. Jacob, J. D. Hoheisel, T. Grehl and H. F. Arlinghaus, Appl. Surf. Sci., 2006, 252, 6742-6745.

146 Y. Nakata, Y. Honda, S. Ninomiya, T. Seki, T. Auki and J. Matsuo, J. Mass Spectrom., 2009, 44, 128-136.

147 V. S. Smentokowski, S. G. Ostrowski, F. Kollmer, A. Schnieders, M. R. Keenan, J. A. Ohlhausen and P. G. Kotula, Surf. Interface Anal., 2008, 40, 1176-1182.

148 R. Mikuba, S. Hassaballa, K. Uchino, H. Yurimoto, R. Todokoro, K. Kumondai and M. Ishihara, Appl. Surf. Sci., 2008, 255(4), 15951598.

149 J. L. Guerquin-Kern, T. D. Wu, C. Quintana and A. Croisy, Biochim. BioPhys. Acta, 2005, 1724(3), 228-238. 